\title{
Vibration control assessment of ASCE benchmark model of cable-stayed bridge
}

\author{
Chin-Hsiung Loh* ${ }^{* \dagger}$ and Chia-Ming Chang \\ Department of Civil Engineering, National Taiwan University, Taipei, Taiwan
}

\begin{abstract}
SUMMARY
This paper presents the performance assessment of the semi-active control on the ASCE benchmark model of a cable-stayed bridge using MR dampers. In order to develop the semi-active control algorithm unique features of the MR damper were generated which considered the intrinsic nonlinear behavior of the damper. The modified nonlinear hysteretic bi-viscous model with three slopes in the force/velocity loop and two yield force values were proposed. Different control algorithms were selected including $\mathrm{H}_{2}, \mathrm{H}_{\infty}$ and mix $\mathrm{H}_{2}$ and $\mathrm{H}_{\infty}$ control algorithms, sliding mode control in lieu of the LQG formulation, and the SMC with fuzzy logic control. The performance of the control algorithm is compared through a numerical study of the ASCE benchmark model of a cable-stayed bridge. Finally, the control performance among different control algorithm is examined. Through numerical study it is concluded that the mixed $\mathrm{H}_{2}$ and $\mathrm{H}_{\infty}$ semiactive control method is the better control method because it has a good ability to mitigate every evaluated response, and has a robust control gain to generate the appropriate control force. But the passive control system (passive-on for MR-damper) for this benchmark problem also provides good control effectiveness. Copyright (C) 2005 John Wiley \& Sons, Ltd.
\end{abstract}

KEY WORDS: MR damper; semi-active control; ASCE phase II benchmark model

\section{INTRODUCTION}

In recent years magnetorheological (MR) dampers have demonstrated a unique ability to create the resisting force following a change of magnetic and fluid field. Due to the sensitivity of MR dampers the dynamic state of the dampers can be generated in milliseconds. Compared with actuators, MR dampers require only low power sources to switch on to the device forces so that no generator is needed to drive the dampers. In past studies, a number of researchers focused on MR damper modeling in order to describe the behavior more completely and correctly, such as the modified Bouc-Wen hysteresis model [1], or the hysteretic bi-viscous model [2]. In numerical studies the Bouc-Wen model [3] can exhibit a wide variety of hysteretic behavior and the Bingham plastic model [4] can also predict the hysteretic behavior effectively. Generally, MR

\footnotetext{
*Correspondence to: Chin-Hsiung Loh, Department of Civil Engineering, National Taiwan University, Taipei, Taiwan.

${ }^{\dagger}$ E-mail: lohc0220@ccms.ntu.edu.tw

Contract /grant sponsor: National Science Council, Taiwan; contract/grant number: NSC92-2211-E-002-087

Received 27 September 2004

Revised 22 November 2004

Copyright (C) 2005 John Wiley \& Sons, Ltd.

Accepted 8 December 2004
} 
dampers are capable of reproducing the resisting forces easily, but inversion from the damper forces to input signal commands is difficult. Therefore, Chang et al. [5] proposed a recurrent inverse neural network (NN) model to approximate the commands of MR dampers. Besides, for the application of MR dampers to control the structure a good control algorithm must also be developed. Yang et al. [6] proposed new optimal control algorithms for structural control using standard quadratic performance and the Ricccati equation to generate the appropriate force. Many theories related to linear quadratic Gaussian (LQG) were demonstrated to produce the optimal force involving $\mathrm{H}_{2}$ and $\mathrm{H}_{\infty}$ control algorithms [7]. Another method for minimization of the structural response is the sliding mode control algorithm (SMC) $[8,9]$. Relying on a specific trajectory, this method was designed with a converging plane to optimize the control force with external disturbance. In contrast to SMC, fuzzy sliding mode control [10] is an intelligent and adaptive method using fuzzy principles in the closed-loop control of nonlinear systems.

In this study, various control algorithms combined with the MR devices are adopted to reduce the seismic response of a bridge structure. The ground motion considered in this study including near-fault and far-field ground motion. Control efficiency is examined through different performance indices. Both passive and active control algorithms are included in this study for comparison. Finally, the ASCE benchmark model of a cable-stayed bridge structure with the installation of MR dampers for numerical verification of the control efficiency is evaluated.

\section{MODELING OF MR DAMPER}

An experimental prototype of a MR damper was provided by NCREE with the capacity for device force, stroke, and velocity are given by $7 \mathrm{kN}, 120 \mathrm{~mm}$, and $380 \mathrm{~mm} / \mathrm{s}$, respectively. The voltage command ranged from 0 to $1.2 \mathrm{~V}$. The hysteretic behavior of the damper, the forcedisplacement and the force-velocity hysteretic loops are generated using sinusoidal displacement command $(120 \mathrm{~mm})$ and fixed frequency $(0.5 \mathrm{~Hz})$, as shown in Figure 1. Seven levels of constant voltages $(0,0.2,0.4,0.6,0.8,1.0$, and $1.2 \mathrm{~V})$ are applied to demonstrate the relation between the yield force and the voltage command.

\section{Modified bi-viscous model}

To assess the ability to predict the behavior of the MR damper, the modified bi-viscous model, as shown in Figure 2, is proposed to improve on the original hysteretic bi-viscous model. The modified bi-viscous model contains six parameters: the pre-yield viscous damping $C_{\mathrm{pr}}$, the postyield viscous damping $C_{\mathrm{po} 1}$ and $C_{\mathrm{po} 2}$, the two yield forces $f_{1}$ and $f_{2}$, and yield velocity respect to the high yield force $v_{1}$. The equations of the piecewise continuous modified bi-viscous model are

$$
\begin{aligned}
& C_{\text {pol }} v-f_{2} \quad v>0 \quad \dot{v} \geqslant 0 \\
& C_{\mathrm{pr}} v-f_{2} \quad 0 \leqslant v \leqslant v_{1} \quad \dot{v} \geqslant 0 \\
& F=\begin{array}{ll}
C_{\mathrm{po} 2}\left(v-v_{1}\right)+f_{1} & v>v_{1} \quad \dot{v} \geqslant 0 \\
C_{\mathrm{po} 1} v+f_{2} & v>0 \quad \dot{v}<0
\end{array} \\
& C_{\mathrm{pr}} v+f_{2} \quad-v_{1} \leqslant v \leqslant 0 \quad \dot{v}<0 \\
& C_{\mathrm{po} 2}\left(v+v_{1}\right)-f_{1} \quad v<-v_{1} \quad \dot{v}<0
\end{aligned}
$$



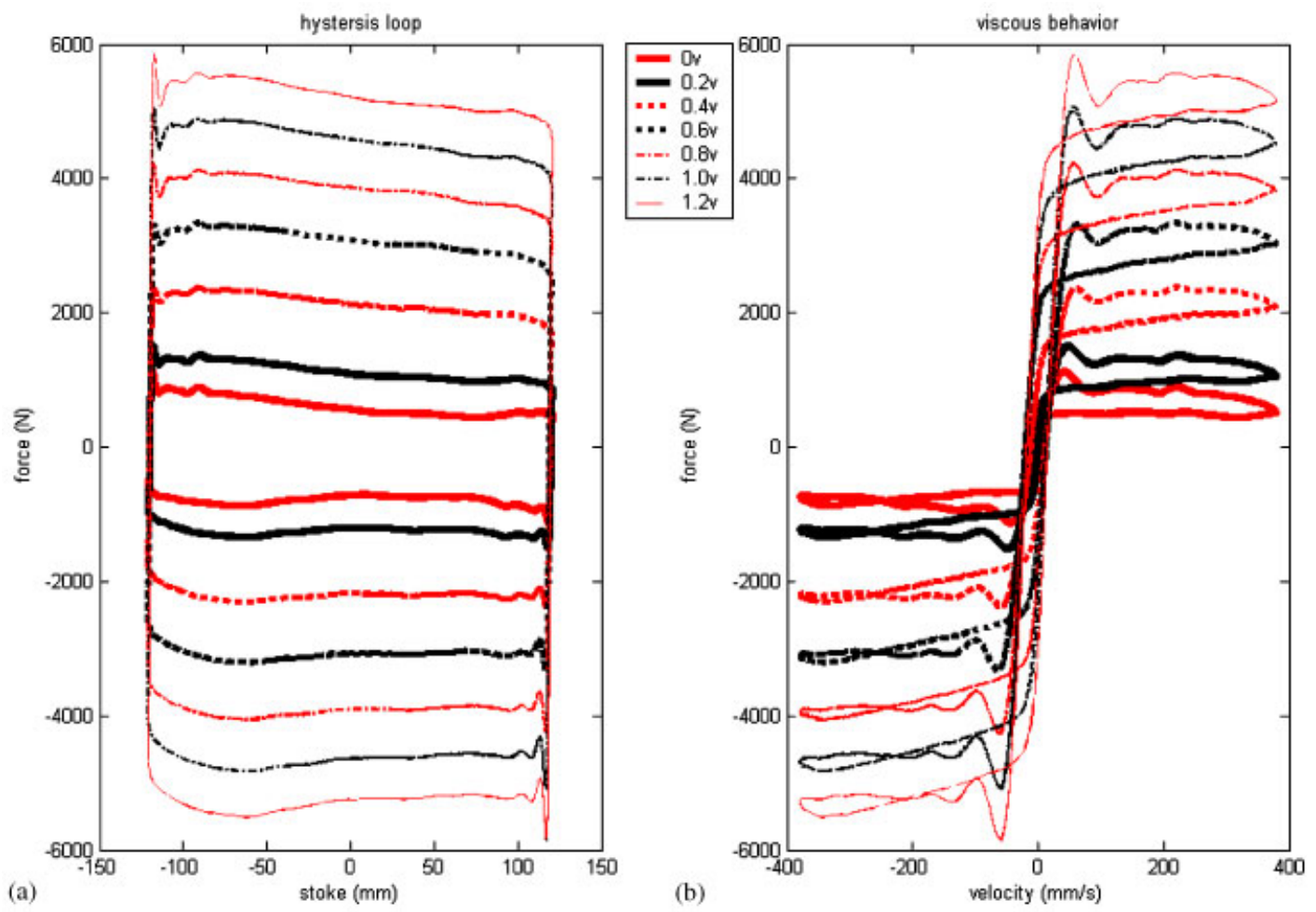

Figure 1. Sinusoidal testing for the MR damper which shows force-stroke and force-velocity relationships.

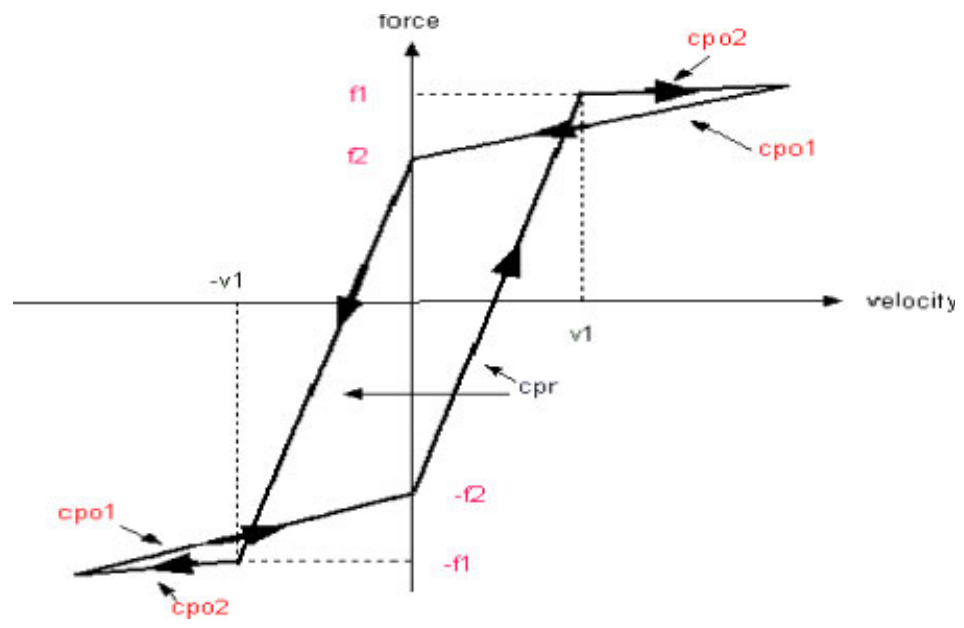

Figure 2. Modified bi-viscous model. 

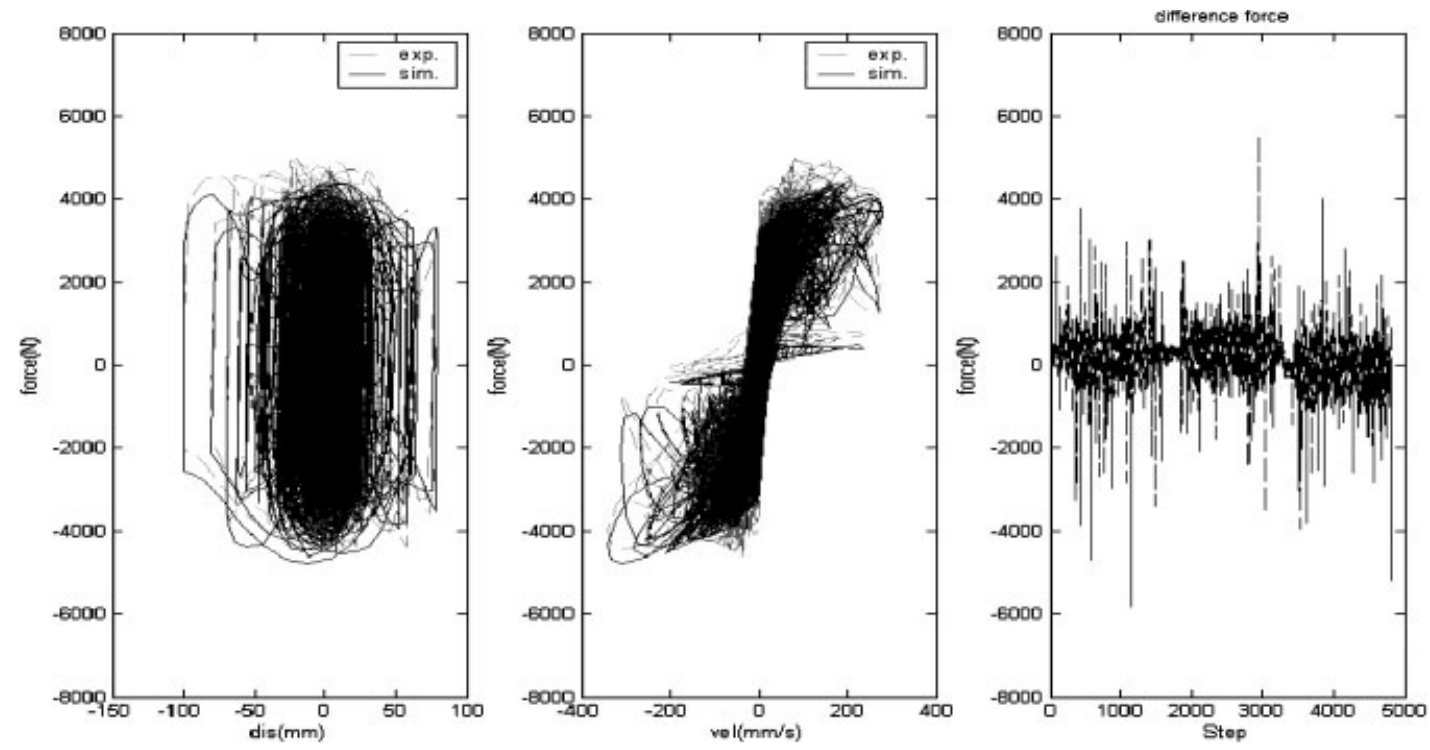

Figure 3. Comparison on hysteretic loop, viscous behavior and error between experimental data and simulated result.

In Equation (1) only five parameters are independent and the pre-yield damping depends on yield velocity and yield forces, $C_{\mathrm{pr}}=\left(f_{1}+f_{2}\right) / v_{1}$, and all parameters were identified by a leastsquares method, minimizing the error between experimental data and mathematical form. The data of sinusoidal test is used to define the polynomial order of all parameters with respect to voltage, and a random test under constant frequency is processed to determine the polynomial coefficients of all model parameters. The first-order polynomial function to fit two post-yield damping(s) and two yield forces with respect to voltage are used and a second-order polynomial function to fit the yield velocity with respect to voltage are used. In Figure 3 the result of the hysteretic behavior between the random data and the modified bi-viscous model is presented and the error of the experimental and simulated force is approximately within the bound of $\pm 100 \mathrm{~N}$ (some exceptional points may reach $600 \mathrm{~N}$ ).

\section{Bilinear model}

Appropriate modeling of control devices is essential to predict the behavior of the controlled system. Following the Bingham model, the model of MR dampers is modified and constructed by a bilinear curve. The behavior of the model is divided into two parts: the pre-yield and the post-yield conditions. The pre-yield damping $C_{\mathrm{pr}}$ is assumed to be much greater than the postyield damping $C_{\mathrm{po}}$, in order to ensure the yield force obtained at low velocity. Figure 4 shows the bilinear model scheme in which there are four independent parameters. The mathematical model can be represented by

$$
\begin{aligned}
& C_{\mathrm{pr}} v \quad-v_{\mathrm{y}} \leqslant v \leqslant v_{\mathrm{y}} \\
& F=C_{\mathrm{po}}\left(v-v_{\mathrm{y}}\right)+f_{\mathrm{y}} \quad v>v_{\mathrm{y}} \\
& C_{\mathrm{po}}\left(v+v_{\mathrm{y}}\right)-f_{\mathrm{y}} \quad v<v_{\mathrm{y}}
\end{aligned}
$$




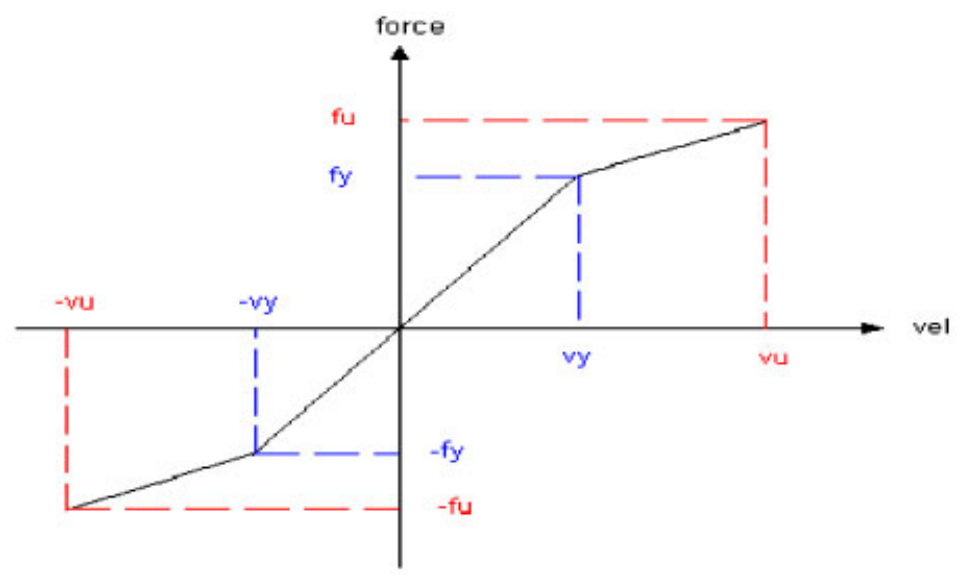

Figure 4. Bilinear model.

where $C_{\mathrm{pr}}$ is the pre-yield damping, $C_{\mathrm{po}}$ is the post-yield damping, $v_{\mathrm{y}}$ is the yield velocity, and $f_{\mathrm{y}}$ is the yield force. Other relevant parameters are the ultimate velocity $v_{\mathrm{u}}$ and the ultimate force $f_{\mathrm{u}}$. The pre-yield damping and the post-yield damping are given by

$$
C_{\mathrm{pr}}=\frac{f_{\mathrm{y}}}{v_{\mathrm{y}}} \quad C_{\mathrm{po}}=\frac{f_{\mathrm{u}}-f_{\mathrm{y}}}{v_{\mathrm{u}}-v_{\mathrm{y}}}
$$

The four independent parameters $f_{\mathrm{y}}, f_{\mathrm{u}}, v_{\mathrm{y}}$, and $v_{\mathrm{u}}$ of bi-viscous model are identified with first-order polynomial functions, but yield velocity uses a second-order polynomial function with respect to voltage. Figure 5 shows the comparison of the hysteretic behavior and the viscous loops between the experimental data and the simulated result. It is important to mention that the bilinear model used in this study consists of three stroke divisions ( $35 \mathrm{~mm}, 35-70 \mathrm{~mm}$, and above $70 \mathrm{~mm}$ ) so that there are three sets of parameters in this model.

\section{Combined bi-viscous and bilinear model}

The model of the MR damper for use in structural control of this study combines the modified bi-viscous model and the bilinear model. The model follows the rules shown in Figure 6. The command voltage is sent to the modified bi-viscous model with the states as inputs and then generates the corresponding force. A constraint function of voltage with a secondorder polynomial function is used to obtain the lower bound of the force. If the corresponding force is greater than the lower bound, the output force is still the force generated by the modified bi-viscous model. On the contrary, the output force is changed to obtain the bilinear model. Therefore, this model combines the characteristics of two models that can be effective to describe the behavior of MR dampers and improve convergency. In a cable-stayed bridge, control is mainly by the bilinear model to estimate the control force generated by MR dampers. 

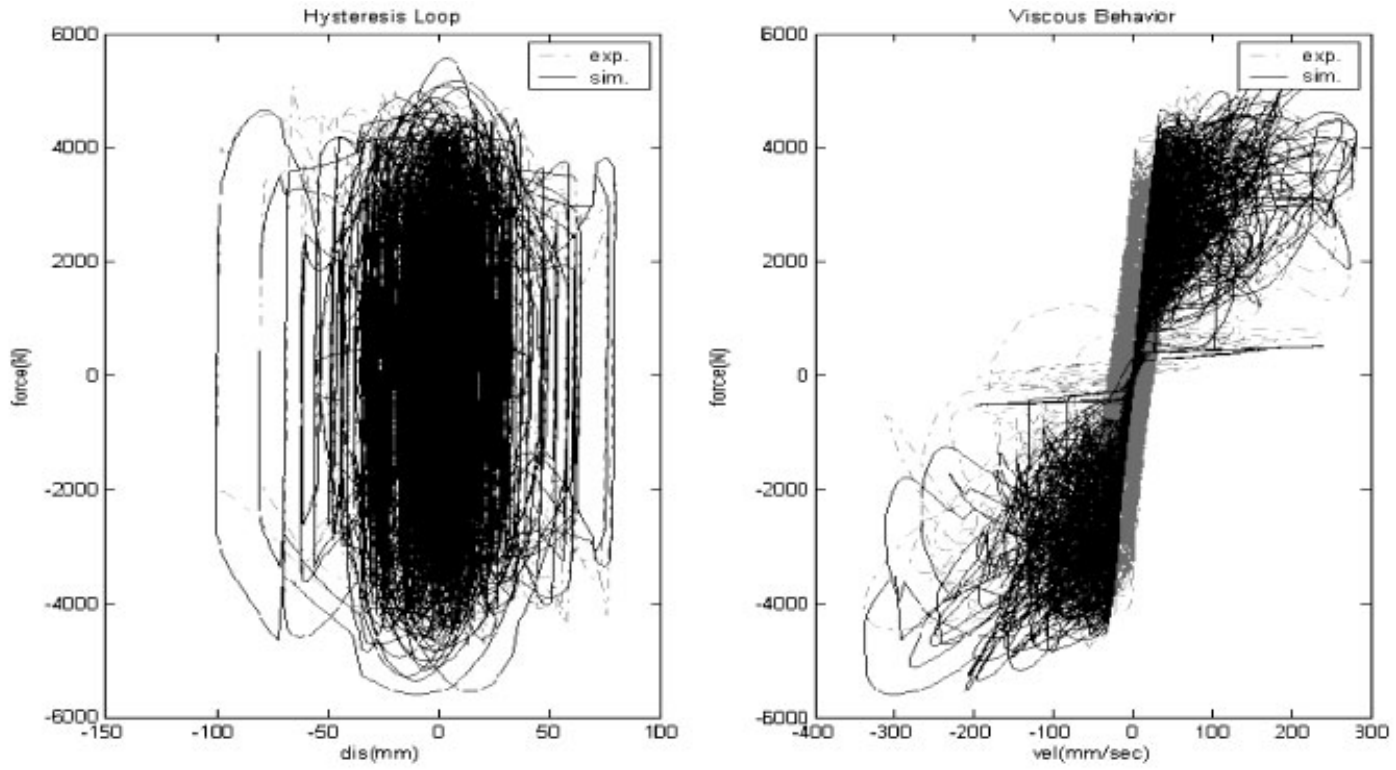

Figure 5. The simulated result compared with the experimental data, including the hysteretic loop and viscous behavior.

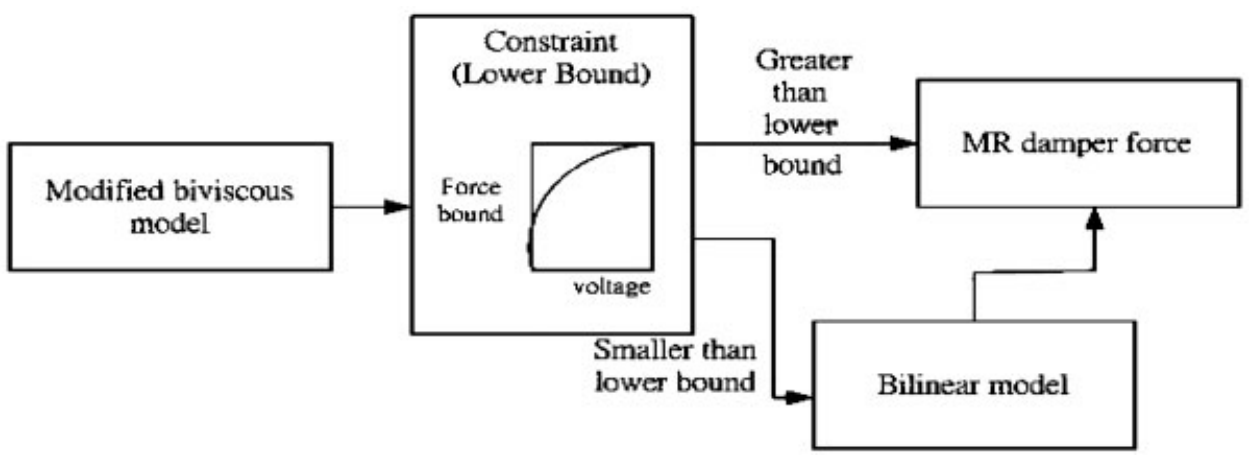

Figure 6. Flowchart of MR damper model.

\section{CONTROL CIRCUIT}

It is assumed that the ASCE benchmark model of a cable-stated bridge subjected to earthquake ground excitation $\ddot{x}_{g}$ is to be controlled using the MR dampers. Figure 7 illustrates a proposed control circuit to realize this objective. Control algorithms are to determine the desired forces based on the response or/and the excitation. The full-state responses are measured or computed to obtain the control force and combined with a Kalman filter to estimate the structural states. The required force needs to consider the capacity of MR 


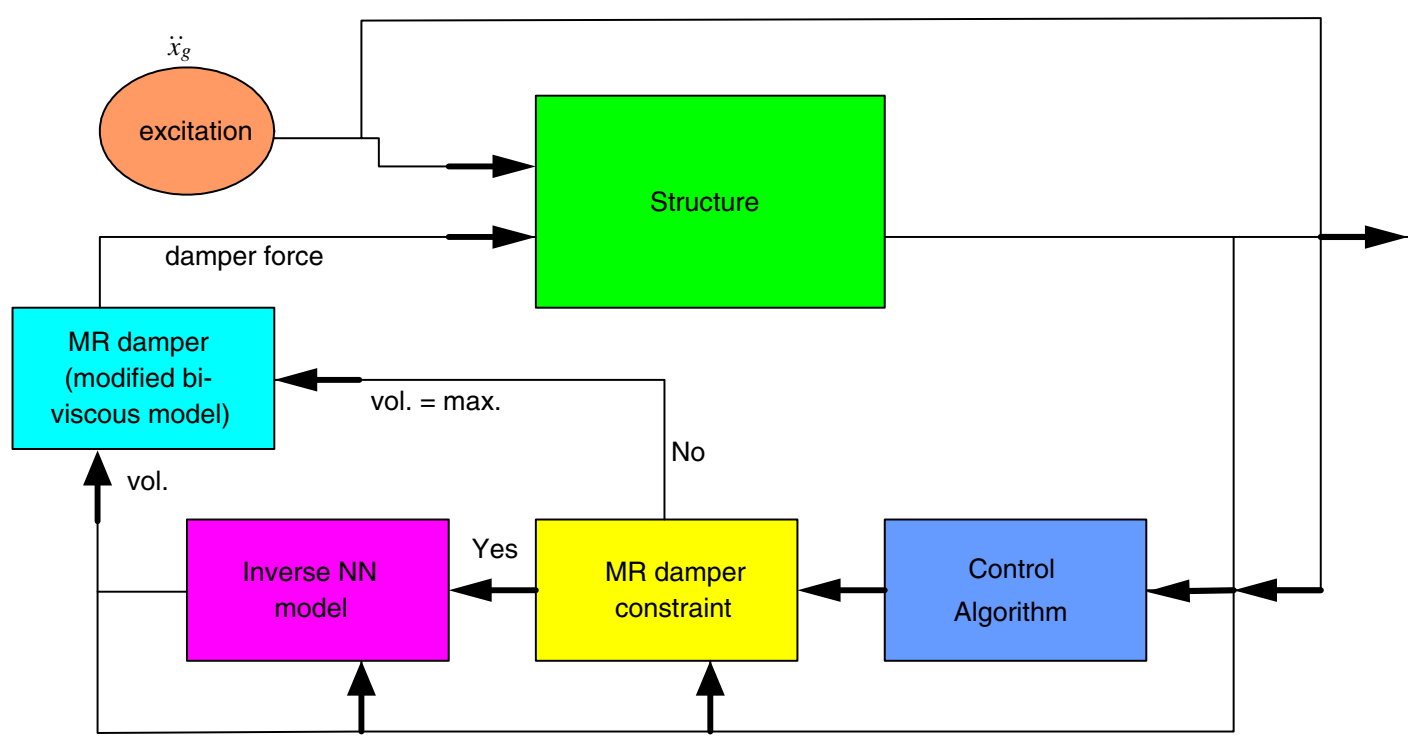

Figure 7. Illustration of control circuit.

dampers for use of the corresponding voltage. When the required force is greater than the maximum force of the MR dampers, the voltage command directly uses the maximum voltage. However, the voltage command can be predicted by using the inverse neural network (NN) model. The inverse NN model is derived from the neural network method to predict the voltage command with previous and present state response and required force. The inputs contain one delay time and current steps of the displacements, one delay time and current steps of velocities, one consecutive step of voltage, and the desired force and the required voltage as the output. Just one hidden layer is selected in this model that includes 12 neurons. The voltage command produced by this powerfully intelligent method is sent into MR dampers. The semi-active control force using the MR damper model can be generated to accomplish the work of minimizing responses. Figure 7 illustrates of the control circuit.

The control algorithms used in this study involve three LQG methods $\left(\mathrm{H}_{2}, \mathrm{H}_{\infty}\right.$, and mixed $\mathrm{H}_{2}, \mathrm{H}_{\infty}$ ) [7], sliding mode control (SMC) [8, 9], and fuzzy sliding mode control (FSMC) [10]. The passive control is also employed in this block to examine the specific MR dampers. The appropriate control force from the control algorithms is sent into the block of control devices, and then the first step is to convert the desired force into the required voltage. The alternative method, following the clipped-optimal concept proposed by Jansen and Dyke [11], which divides the voltage range into 121 segments of $0.1 \mathrm{~V}$, is adopted in this study. Every incremental voltage uses the bilinear model to approach the desired force with the minimum error compared with the generated force. In addition, the second step of the control device block is to utilize the estimated voltage to drive the MR dampers. The completed control procedure allows the proposed circuit to simulate the evaluation model under various seismic excitations and compares each control algorithm with the performance criteria. 


\section{CONTROL APPLICATION TO CABLE-STAYED BRIDGE}

To verify the effectiveness of the proposed control strategies, a set of control simulations specified in the ASCE benchmark problem is performed using the selected three ground motions from three historical earthquakes, which include three conventional earthquakes and the ChiChi earthquake in Taiwan. A three-dimensional finite element model of the bridge, as shown in Figure 8, is developed in the linear evaluation model. The ASCE benchmark problem considers the cable-stayed bridge scheduled for completion in Cape Girardeau, Missouri, in 2003. The bridge is composed of two towers, 128 cables, and 12 additional piers. It has a total length of $1205.8 \mathrm{~m}$. The main span is $350.6 \mathrm{~m}$ in length, the side spans are $142.7 \mathrm{~m}$ in length, and the approach on the other side is $570 \mathrm{~m}$. The 128 cables are made of high-strength, low-relaxation steel. The smallest cable area is $28.5 \mathrm{~cm}^{2}$ and the largest cable area is $76.3 \mathrm{~cm}^{2}$. The damping matrix is developed by assigning 3\% of critical damping to each mode. The stiffness matrices in this linear model are those of the structure determined through a nonlinear static analysis corresponding to the deformed state of the bridge with dead loads; furthermore, the bridge is assumed to be attached to bedrock, neglecting the effects of soil-structure interaction. The static condensation to the full finite element model of the bridge is applied to construct a 579 degrees-
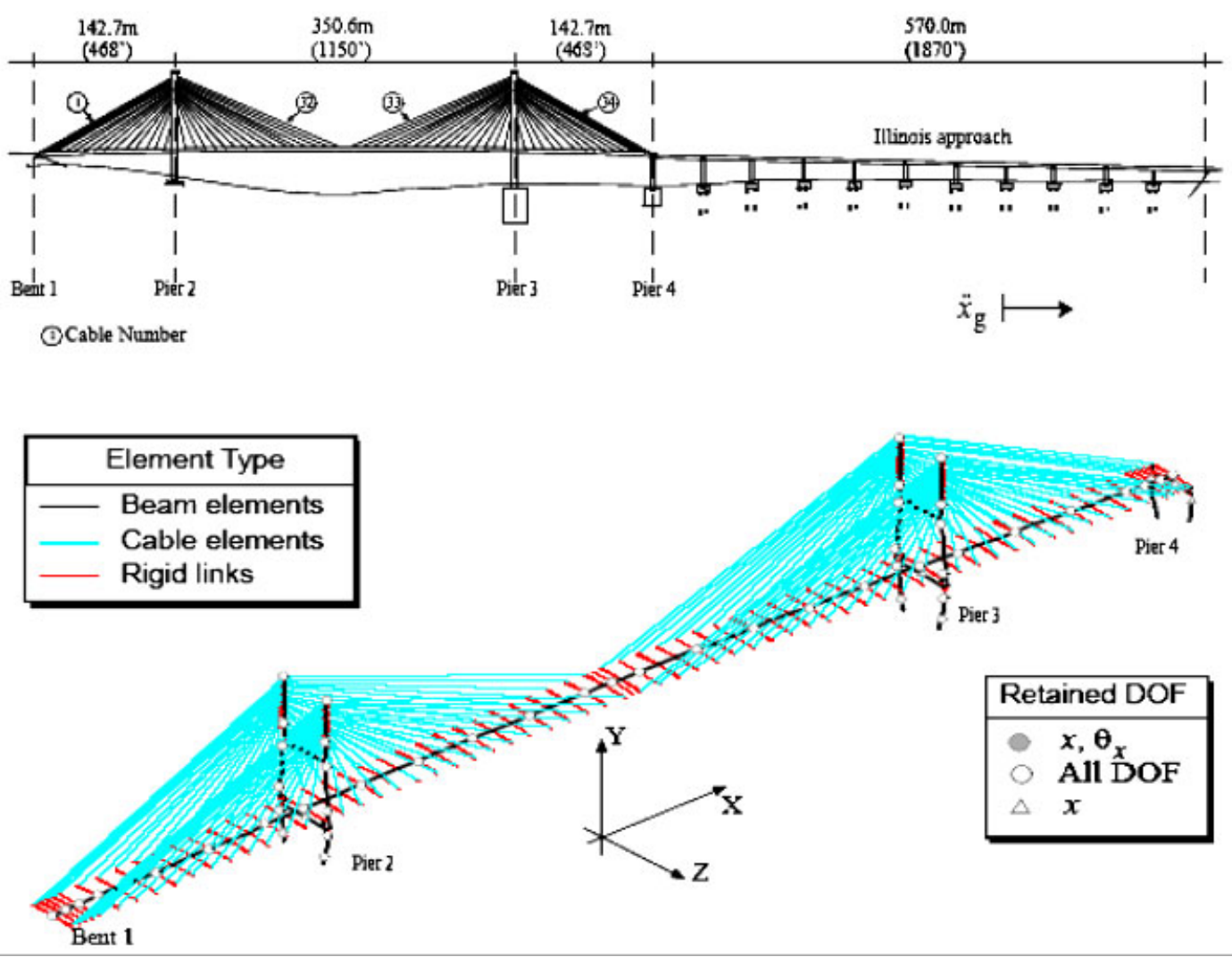

Figure 8. A three-dimensional finite element model of the bridge [12]. 
of-freedom model. The first ten undamped frequencies of the evaluation model are 0.1619 , $0.2667,0.3725,0.4547,0.5017,0.5653,0.6190,0.6489,0.6968$, and $0.7097 \mathrm{~Hz}$.

The sensors and control devices interface with the bridge model through measurement and connection outputs, designated $y_{\mathrm{m}}$ and $y_{\mathrm{c}}$, respectively; furthermore, the components of the evaluation are defined as $y_{\mathrm{e}}$. The efficiency of the control reality is considered so that a reduced order model needs to be developed through balanced realization of the system and subsequent condensation of the full states. The sensor block contains accelerometers and displacement transducers to send into a design model that selects main 30 states for use in developing the control force. Based on the reduced order model, the controller can easily design the inputs with respect to the control algorithms.

In the control of civil engineering structures absolute acceleration measurements are readily available. Additionally, measurements of the control devices themselves are typically available. Six accelerometers are placed on top of the tower legs, including four oriented to measure longitudinal acceleration, and two to measure transverse accelerations. Eight accelerometers are placed on the deck, including one at mid-span oriented to measure longitudinal accelerations, and seven oriented to measure transverse accelerations. Two displacement sensors are positioned between the deck and pier 2, and two displacement sensors are located between the deck and pier 3. Eight displacement sensors and eight velocity sensors are located where the control devices apply into measure the connecting response.

In addition, a virtual damper was adopted for the large-scale model, using the bilinear model. The three conventional earthquakes records considered in the benchmark problem are the 1940 El Centro, the 1985 Mexico City, and the 1999 Gebze; the Chi-Chi earthquake input is from Stations TCU052, TCU102, and TCU111. In order to verify the control effectiveness on the ground motion excitation with long period waves, the 1985 Mexico City ground motion was select as one of the excitations in this study. The near-fault ground motion data from the ChiChi earthquake (Stations TCU052, TCU102) was also selected. To approach the real conditions under the specific excitations, the effects of the time-delayed input are considered in the multisupport problem based on the distance between adjacent supports and propagating with the speed of the L-wave of a typical earthquake in the longitudinal direction. A total of $24 \mathrm{MR}$ dampers are considered as control devices. Four devices are located between each of the following pairs of nodes on bent 1 and piers 4; and, two devices are located between each of the following pairs of nodes on piers 2 and 3. Herein, two types of MR dampers are employed to control the evaluation model essentially. One is the small-scale MR dampers provided by NCREE with $7 \mathrm{kN}$ maximum resisting force for each and the capacity was amplified to 100 times with respect to the original experimental data so as to adapt to the large-scale bridge. The other type of MR dampers referred to the former ones is created with the bilinear model by using reasonable model parameters. The second type of MR dampers is called 'virtual' MR dampers in this study, with the range of the voltage command and the capacity of the control force $0-2.5 \mathrm{~V}$ and $1000 \mathrm{kN}$, respectively. Table I shows the relative parameters of MR dampers with respect to voltage. The simulation examples under the conventional excitations obey the capacity rules of two types of MR dampers, but the examples using Taiwan events may exceed the capacity of the prior description due to the larger peak ground acceleration of these events.

Eighteen criteria have been defined [12] to evaluate the capabilities of each control strategy. In this study, the longitudinal performance of the bridge is considered as a relatively important subject so that eleven of these criteria are selected for use. The first five evaluation criteria $\left(J_{1}-J_{5}\right)$ consider the ability of the controller to reduce the peak response. $J_{1}$ and $J_{2}$ are ratios of 
Table Ia. Parameters of the original MR damper.

\begin{tabular}{c}
\hline Modified biviscous model (displacement $\leqslant 50 \mathrm{~mm})$ \\
\hline$v_{1}=19.493 \mathrm{vol}^{4}-10.01 \mathrm{vol}^{3}-4.3162 \mathrm{vol}^{2}+29.128$ \\
$C_{\mathrm{po} 1}=-7.7829 \mathrm{vol}^{2}+12.949 \mathrm{vol}^{2}+1.759, C_{\mathrm{po} 2}=-6.9661 \mathrm{vol}^{2}+12.219 \mathrm{vol}-0.42472$ \\
$f_{1}=-559.96 \mathrm{vol}^{2}+3481.2 \mathrm{vol}+481.5, f_{2}=-672.73 \mathrm{vol}^{2}+3523.3 \mathrm{vol}+74.052$ \\
\hline Modified biviscous model $($ displacement $>50 \mathrm{~mm})$ \\
$v_{1}=75.128 \mathrm{vol}^{4}-170.02 \mathrm{vol}^{3}+104.86 \mathrm{vol}^{2}+10.681 \mathrm{vol}+0.96803$ \\
$C_{\mathrm{po} 1}=-5 \mathrm{vol}^{2}+12.918 \mathrm{vol}-1, C_{\mathrm{po} 2}=-8.5365 \mathrm{vol}^{2}+11.574 \mathrm{vol}+0.10472$ \\
$f_{1}=-195.03 \mathrm{vol}^{2}+3235.8 \mathrm{vol}+487.18, f_{2}=-948.61 \mathrm{vol}^{2}+3530.9 \mathrm{vol}+239.27$ \\
\hline
\end{tabular}

Table Ib. Parameters (or functions) for two types of MR dampers in the control of cable-stayed bridge.

\begin{tabular}{lcc}
\hline \multicolumn{3}{c}{ Original MR dampers } \\
\hline Under $0.35 \mathrm{~m}$ & $0.35-0.7 \mathrm{~m}$ & Over $0.7 \mathrm{~m}$ \\
\hline$f_{\mathrm{u}}=947.95 \mathrm{vol}+18.985$ & $f_{\mathrm{u}}=774.6 \mathrm{vol}+41.463$ & $f_{\mathrm{u}}=625.91 \mathrm{vol}+41.757$ \\
$f_{\mathrm{y}}=275.12 \mathrm{vol}+43.928$ & $f_{\mathrm{y}}=286.45 \mathrm{vol}+50.921$ & $f_{\mathrm{y}}=293.77 \mathrm{vol}+52.429$ \\
$v_{\mathrm{y}}=-6.9203 \mathrm{vol}^{2}+23.555 \mathrm{vol}+8.8603$ & $v_{\mathrm{y}}=12.372 \mathrm{vol}+18.866$ & $v_{\mathrm{y}}=18.106 \mathrm{vol}+5.1088$ \\
$v_{\mathrm{u}}=564.28 \mathrm{vol}+78.821$ & $v_{\mathrm{u}}=932.41 \mathrm{vol}+61.779$ & $v_{\mathrm{u}}=658.57 \mathrm{vol}+192.98$ \\
& $f_{\mathrm{u}}$ and $f_{\mathrm{y}}: \mathrm{kN}, v_{\mathrm{y}}$ and $v_{\mathrm{u}}: \mathrm{cm} / \mathrm{s}$ \\
& Virtual MR dampers \\
$f_{\mathrm{u}}=420 \mathrm{vol}+150, f_{\mathrm{y}}=212 \mathrm{vol}+120, v_{\mathrm{y}}=0.04 \mathrm{vol}+0.35, v_{\mathrm{u}}=0.04 \mathrm{vol}+0.8$ \\
\\
$f_{\mathrm{u}}$ and $f_{\mathrm{y}}: \mathrm{kN}, v_{\mathrm{y}}$ and $v_{\mathrm{u}}: \mathrm{m} / \mathrm{s}$ \\
vol: voltage command
\end{tabular}

the maximum controlled shear forces normalized to those of the uncontrolled cases at the base and at the deck, respectively. $J_{3}$ and $J_{4}$ are ratios of the maximum controlled moments normalize to those of the uncontrolled cases at the same locations. $J_{5}$ considers the peak deck displacement normalized to the maximum of the deck response at pier 1 and 4 . The next four criteria $\left(J_{6}-J_{9}\right)$ consider normed responses over the entire simulation time. $J_{6}$ and $J_{7}$ are ratios of the normed values of the base shear and the shear normalized to the maximum of those of the uncontrolled cases at deck in the towers, respectively. $J_{8}$ and $J_{9}$ are ratios of the normed values of the overturning moment and the moment normalize to the maximum of those of the uncontrolled cases at the deck in the towers. $J_{10}$ considers the ratio of the maximum of control forces normalized to the seismic weight of the bridge, based on the mass of the superstructure. $J_{11}$ is focused on the maximum stroke of the control devices normalized to the maximum uncontrolled displacement at the top of the towers relative to the ground.

\section{RESULTS OF ANALYSIS}

Through the simulation study, the consequence of analytical result using original MR dampers and using virtual MR dampers under conventional excitations (1940 El Centro, 1985 Mexico, 
and 1999 Gebze earthquakes) and Chi-Chi earthquake ground motions, is discussed. All the ground motion data were recorded at hard site conditions except the 1985 Mexico earthquake ground motion. Since most of the bridge is assumed to be located at hard site conditions, the reason for choosing the Mexico earthquake ground motion is to verify the control efficiency due to the effect of long-period seismic waves. The first type of result (Figure 9) shows the comparison of the responses of the controlled bridge with those of the uncontrolled bridge for the three earthquakes. The second type (Figure 10) shows the maximum and minimum cable tension as a function of cable number. The outer region provides the acceptable range of cable tensions as specified constraints. The constraints limit the cable tension between 20 and $70 \%$ of the tension capacity for the conventional earthquakes. The central region provides a graphical description of the actual minimum and maximum cable tension. The third type (Figure 11) uses bar charts to show the performance indices $\left(J_{1}-J_{4}\right.$ and $\left.J_{6}-J_{9}\right)$. These bar charts show only base shear responses because other performance indices are difficult to judge by means of bar charts. Finally, Table II shows the ranking values of the proposed evaluation criteria for semi-active control methods, including summation of all performance indices $\left(J_{1}-J_{11}\right)$.

For the case of the original MR dampers Figure 9 shows the comparison on base shear time histories of pier 2 with passive-on $(1.2 \mathrm{~V})$ control, mixed $\mathrm{H}_{2}$ and $\mathrm{H}_{\infty}$ control strategy and the uncontrolled case by using input motion from the El Centro, Mexico, Gebze and Chi-Chi

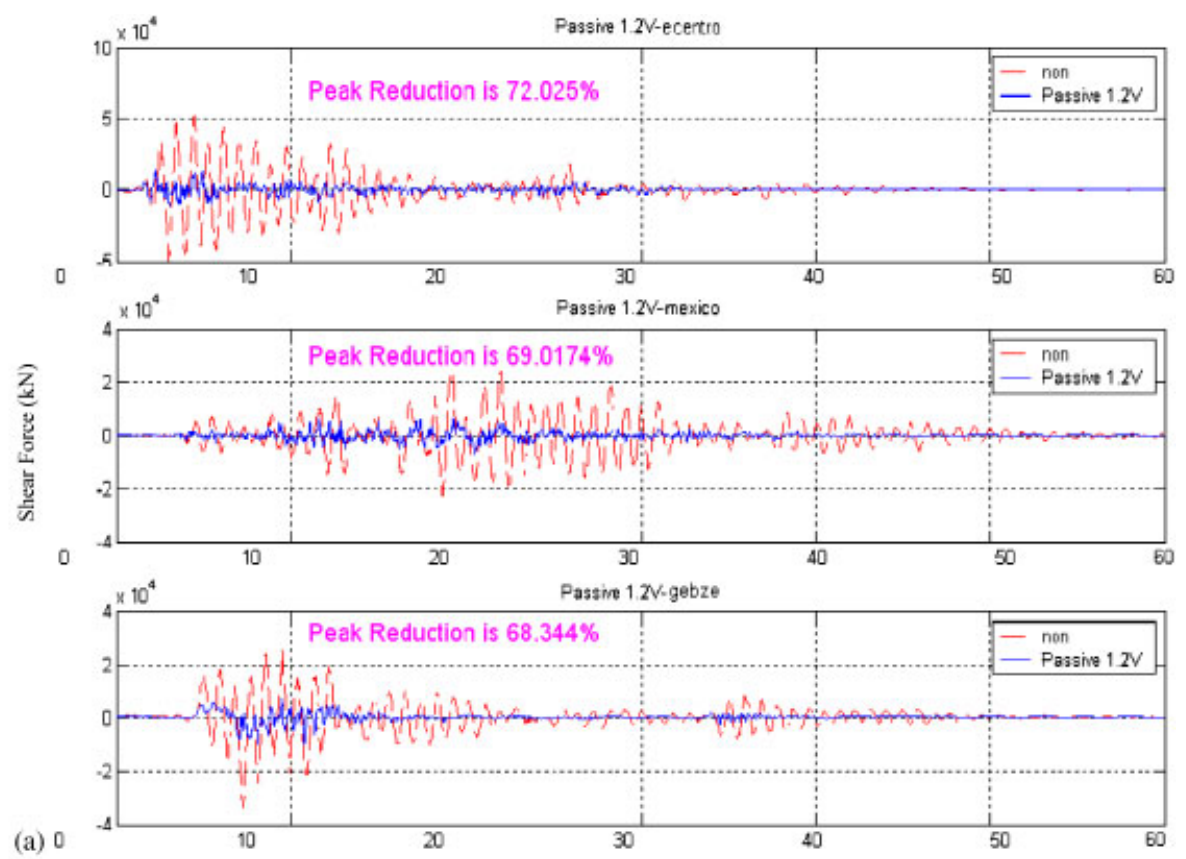

Figure 9. (a) Simulated responses to El Centro, Mexico, and Gebze earthquakes using original MR dampers with passive-on $(1.2 \mathrm{~V})$ control method (uncontrolled and controlled base shear force record on pier 2); (b) simulated responses to El Centro, Mexico, and Gebze earthquakes using original MR dampers with mixed $\mathrm{H}_{2}$ and $\mathrm{H}_{\infty}$ control method (uncontrolled and controlled base shear force record on pier 2); (c) simulated responses to TCU052, TCU102, and TCU111 earthquakes using mixed $\mathrm{H}_{2}$ and $\mathrm{H}_{\infty}$ control method of original MR dampers (uncontrolled and controlled base shear force record on pier 2). 

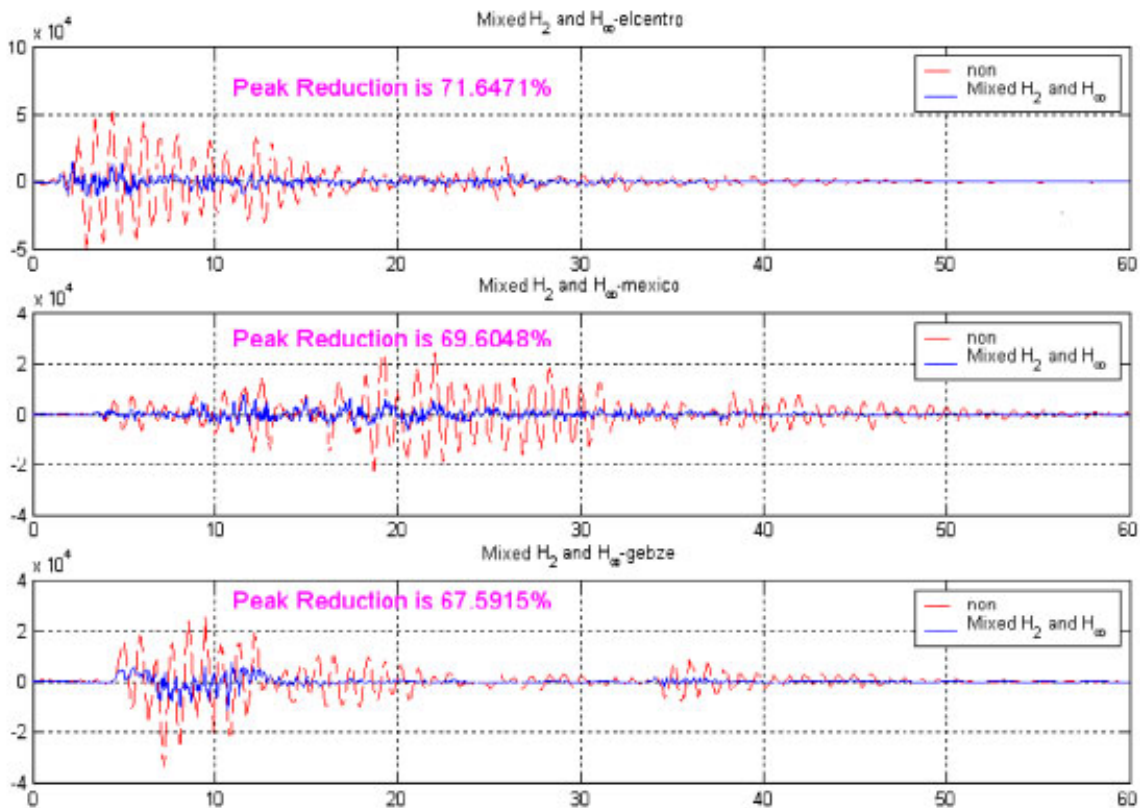

(b)
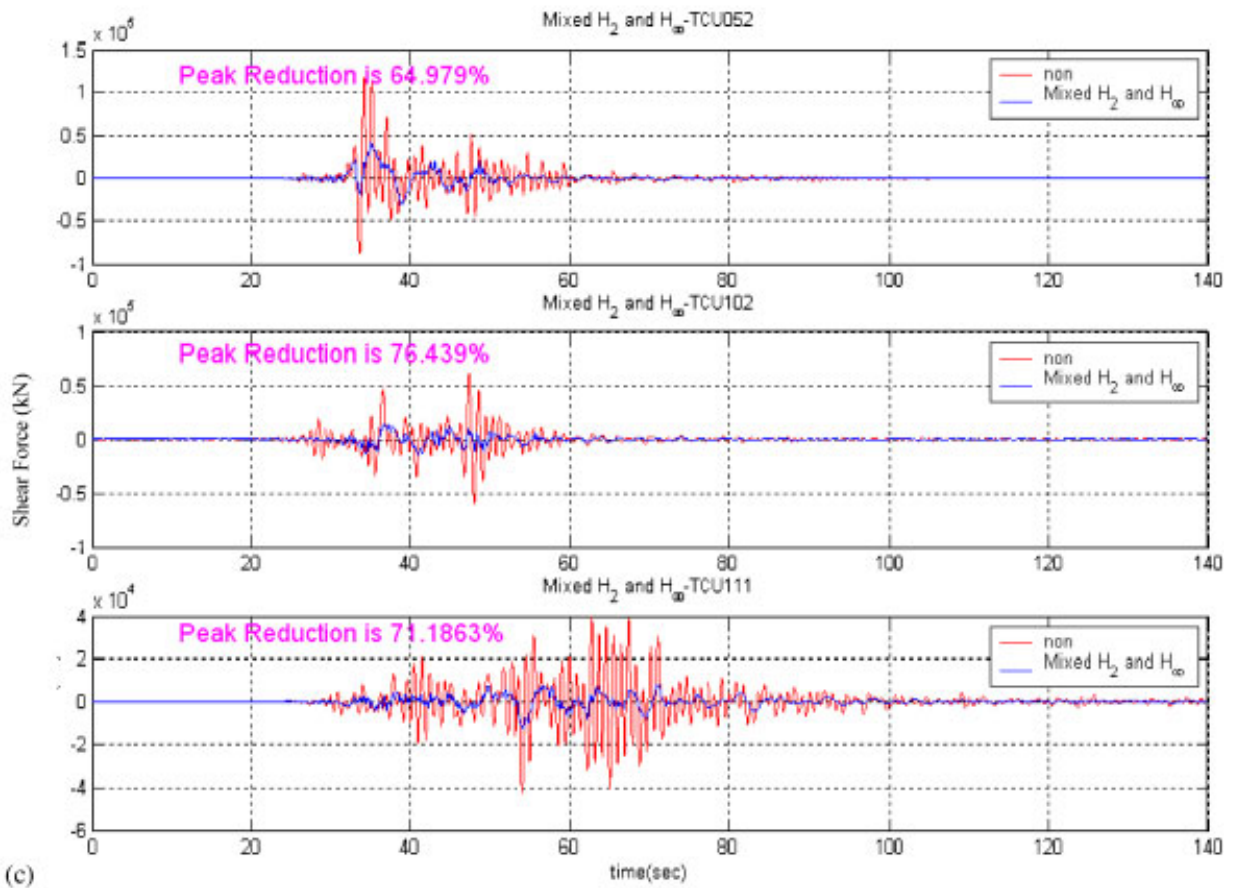

(c)

Figure 9. Continued. 
earthquakes. Figure 10 shows the acceptable cable tension between the provided ranges after the control. Figure 11(a) shows the performance indices, $J_{1}, J_{3}, J_{6}$, and $J_{8}$, under El Centro earthquake excitation for different control methods, and Figure 11(b) shows the performance indices, $J_{2}, J_{4}, J_{7}$, and $J_{9}$, under El Centro earthquake excitation. Figure 11(c) shows the performance indices, $J_{1}, J_{3}, J_{6}$, and $J_{8}$, under the excitation of the Chi-Chi earthquake TCU102 data. The sequence in horizontal axis of Figure 11 denotes: (a) passive-off $(0 \mathrm{~V})$ control; (b) passive $\left(0.6 \mathrm{~V}\right.$ ) control; (c) passive-on (1.2 V) control; (d) $\mathrm{H}_{2}$ semi-active control; (e) $\mathrm{H}_{\infty}$ semiactive control; (f) mixed $\mathrm{H}_{2}$ and $\mathrm{H}_{\infty}$ semi-active control; (g) SMC; and (h) FSMC. Table II shows the ranking value of evaluation criteria with respect to each semi-active control algorithm. For virtual MR dampers Figures 12-14 show the corresponding results. Discussion of this case study is described as follows:

1. The passive-on $(1.2 \mathrm{~V})$ control method gives 72,69 , and $68.3 \%$ reduction in peak base shear responses under El Centro, Mexico, and Gebze earthquakes, respectively. The best semi-active control method under three different earthquakes is demonstrated to be the mixed $\mathrm{H}_{2}$ and $\mathrm{H}_{\infty}$ semi-active control method which has $71.6 \%$ reduction in peak base
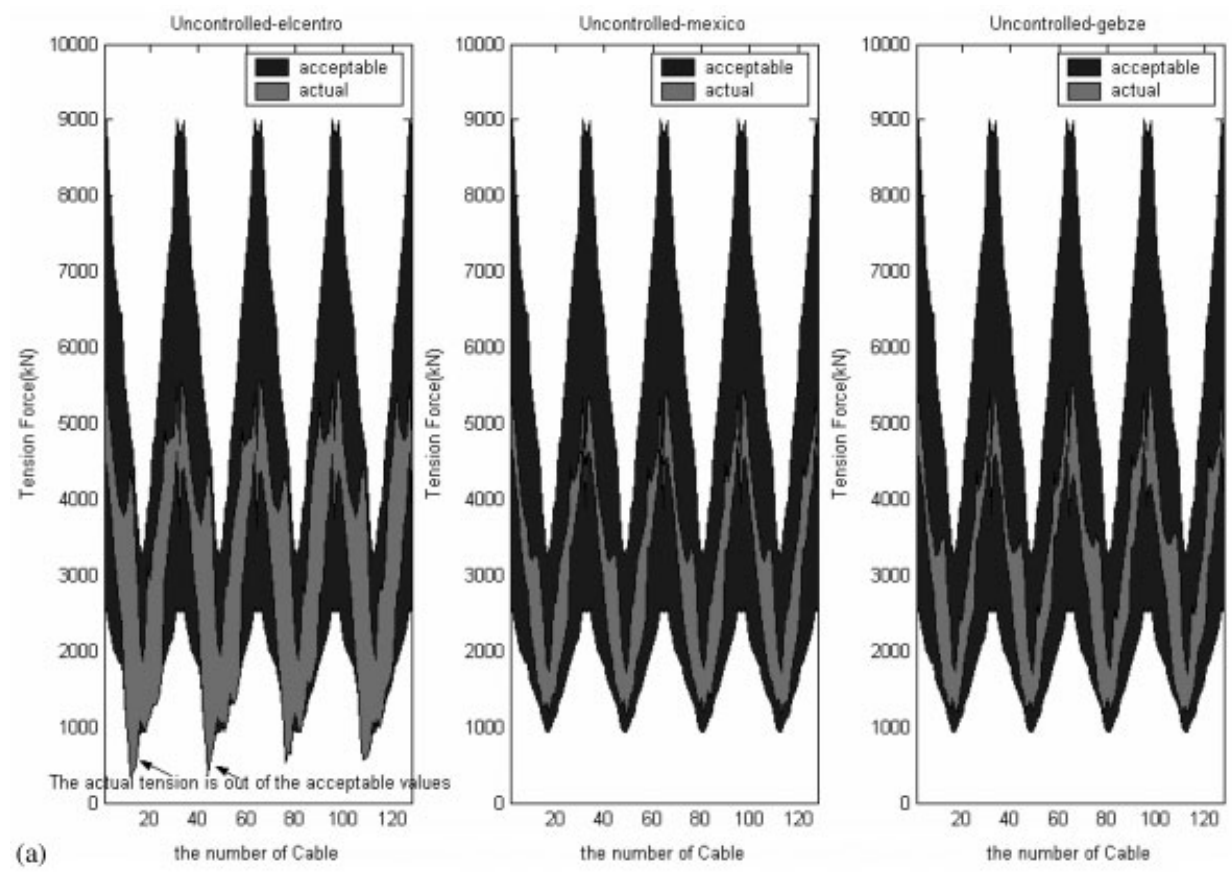

Figure 10. (a) Simulated responses of uncontrolled cable tension under El Centro, Mexico, and Gebze earthquakes; (b) simulated responses of controlled cable tension using passive-off ( $1.2 \mathrm{~V}$ ) control method of original MR dampers under El Centro, Mexico, and Gebze earthquakes; (c) simulated responses of controlled cable tension using mixed $\mathrm{H}_{2}$ and $\mathrm{H}_{\infty}$ control method of original MR dampers under El Centro, Mexico, and Gebze earthquakes; (d) simulated responses of uncontrolled cable tension under TCU052, TCU102, and TCU111 earthquakes; (e) simulated responses of controlled cable tension using mixed $\mathrm{H}_{2}$ and $\mathrm{H}_{\infty}$ control method of original MR dampers under TCU052, TCU102, and TCU111 earthquakes. 

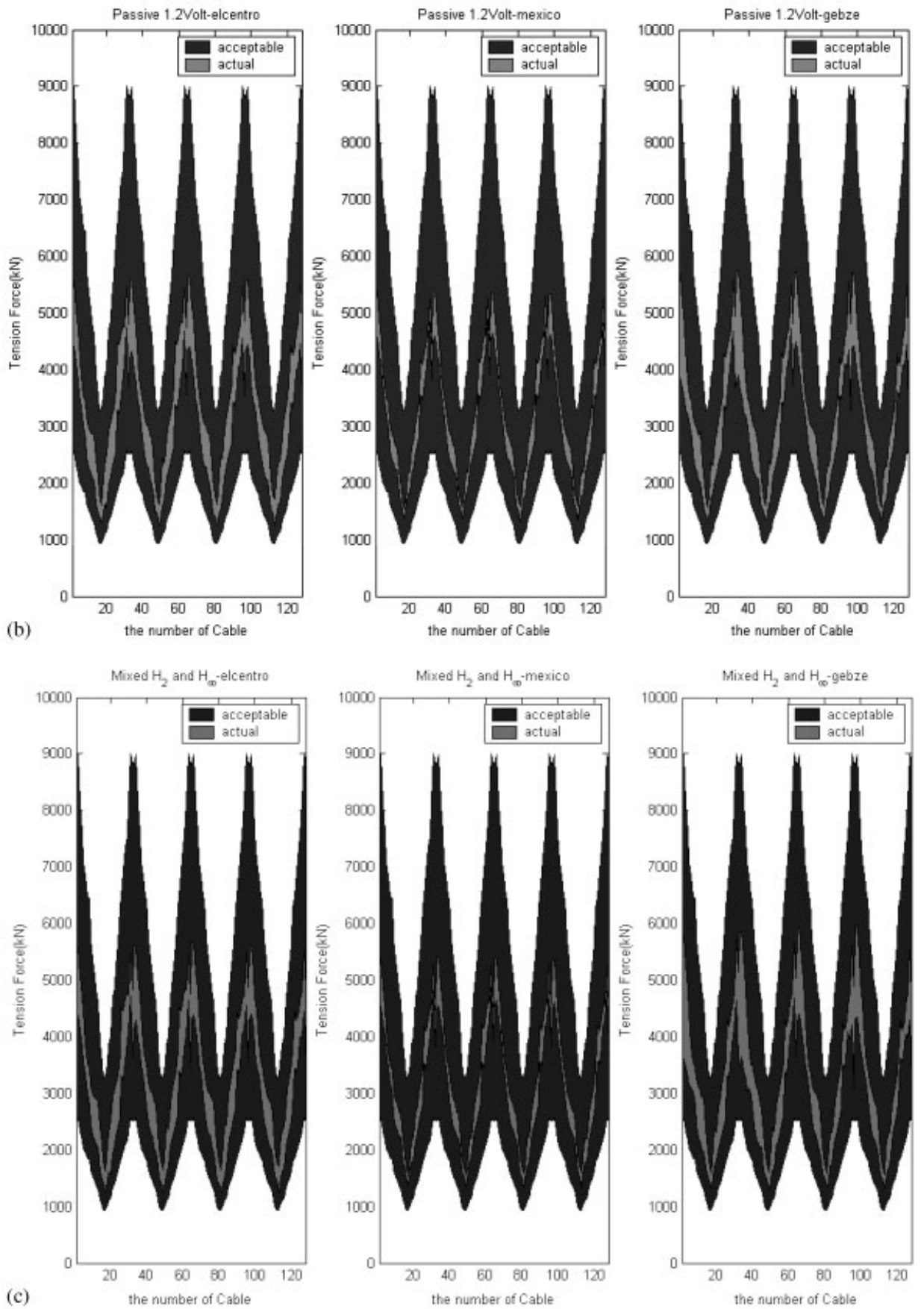

Figure 10. Continued. 

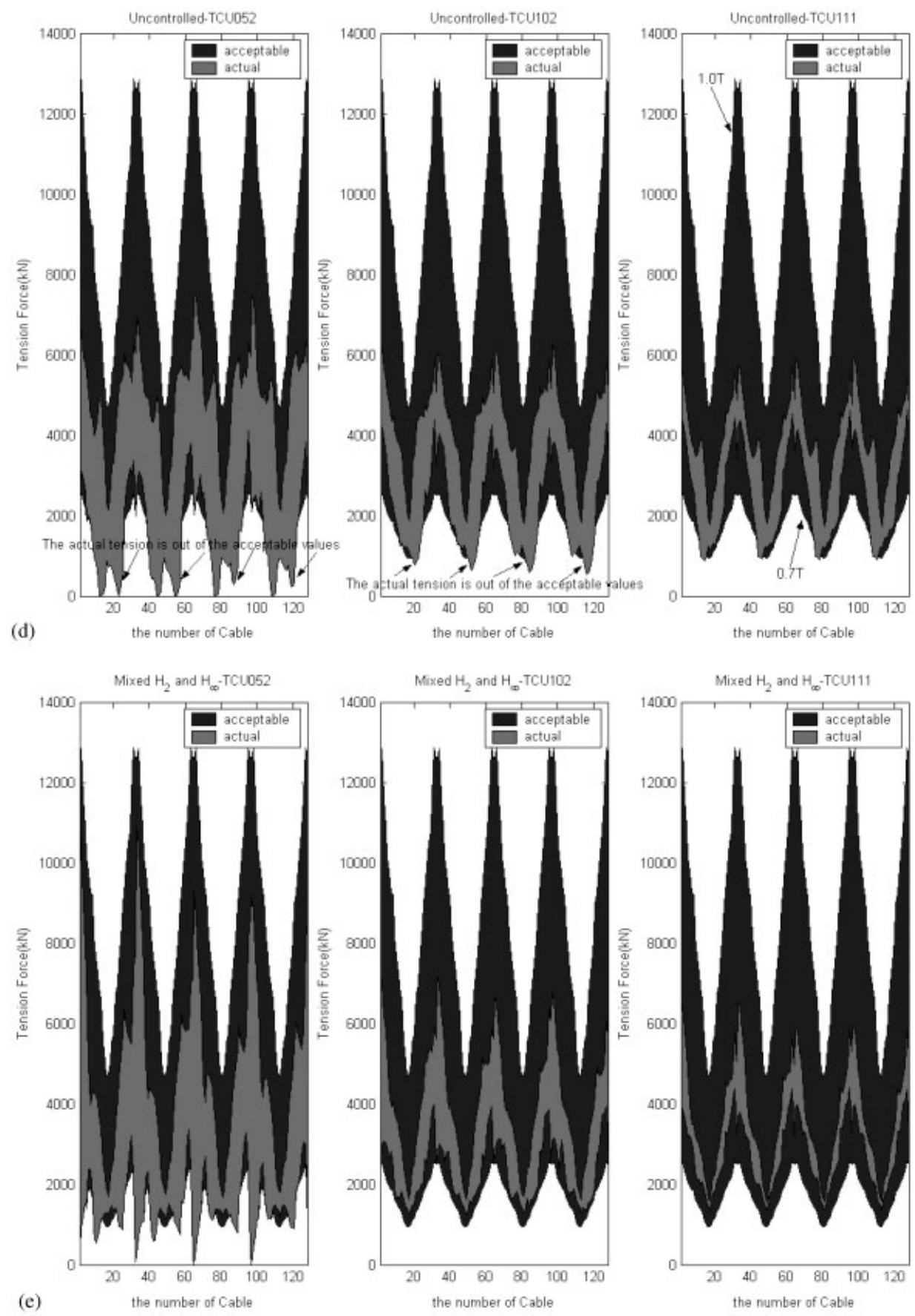

Figure 10. Continued. 

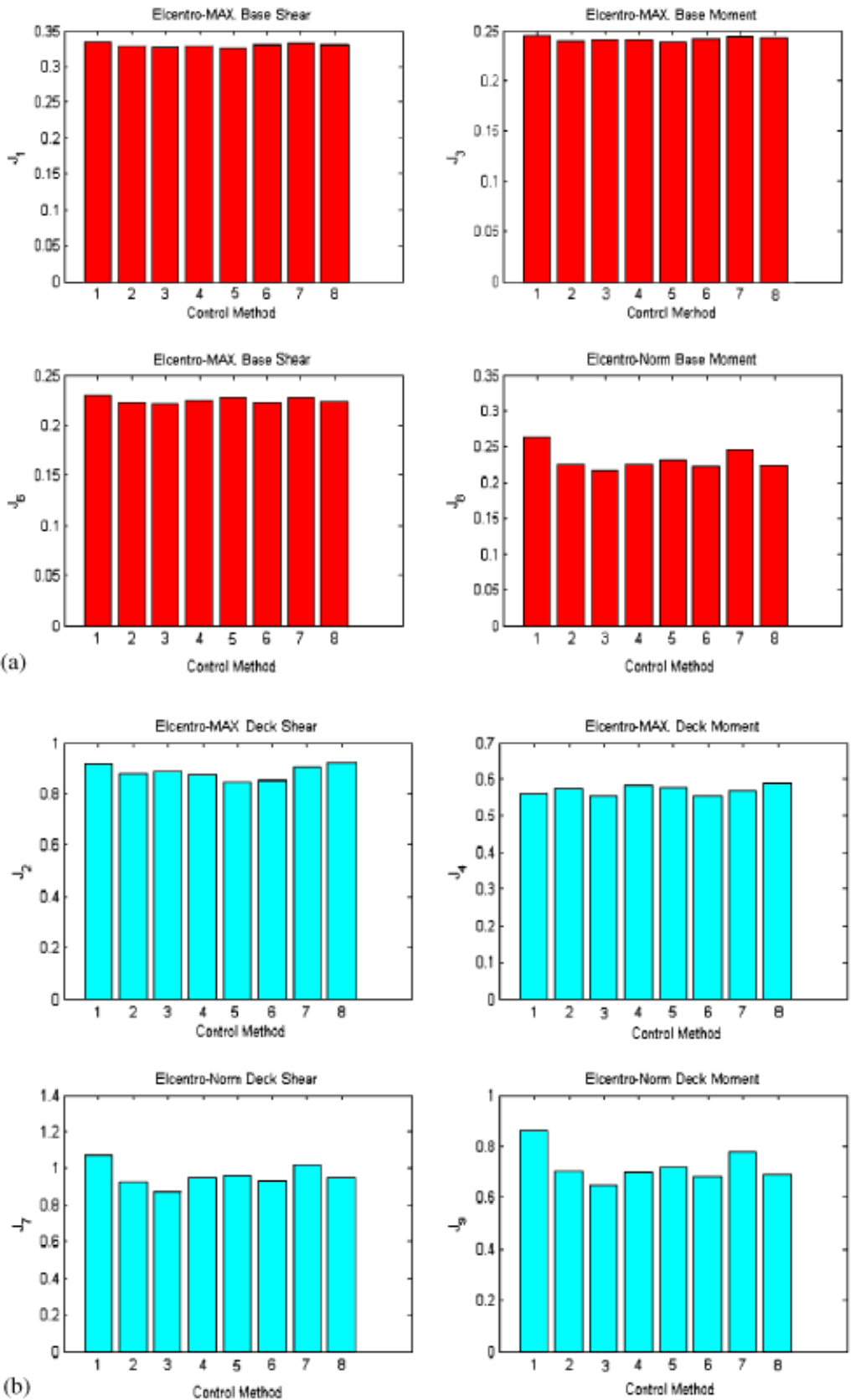

Figure 11. (a) Comparison of performance indices $\left(J_{1}, J_{3}, J_{6}\right.$, and $\left.J_{8}\right)$ of the cases using original MR dampers under the El Centro earthquake; (b) comparison of performance indices $\left(J_{2}, J_{4}, J_{7}\right.$, and $\left.J_{9}\right)$ of the cases using original MR dampers under the El Centro earthquake; (c) comparison on performance indices $\left(J_{1}, J_{3}, J_{6}\right.$, and $\left.J_{8}\right)$ of the cases using original MR dampers under the TCU102 earthquake. 

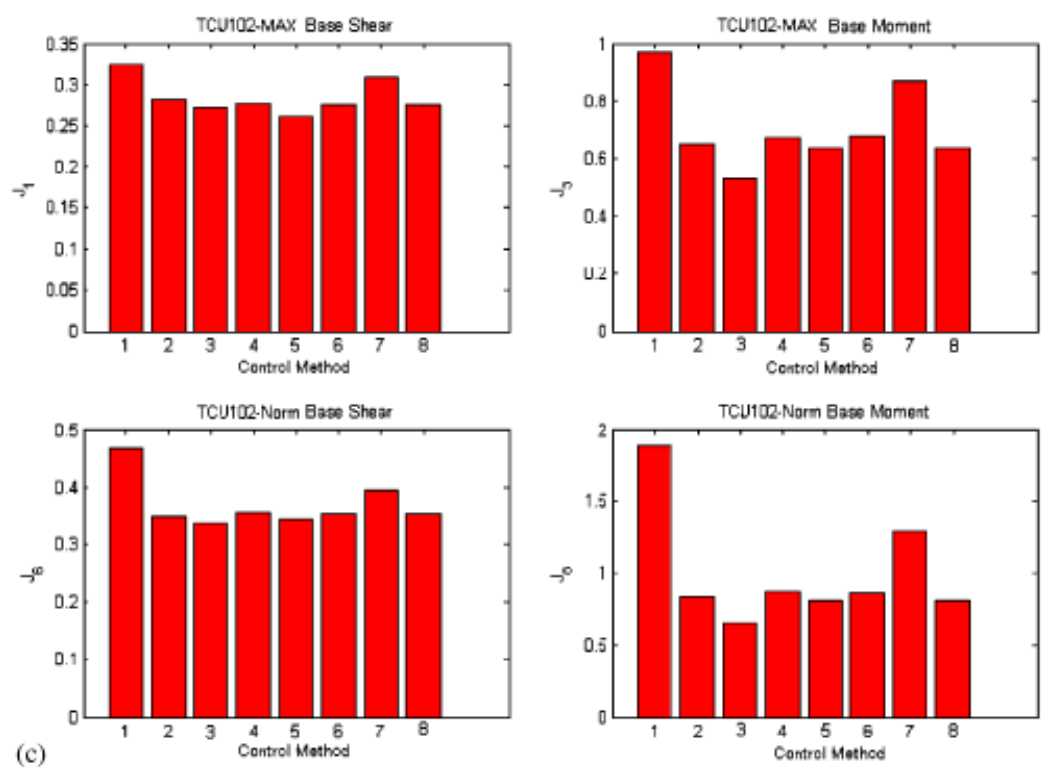

Figure 11. Continued.

shear response under the El Centro earthquake. The SMC semi-active method has $70.7 \%$ reduction in peak base shear responses under the Mexico earthquake. The FSMC semiactive method has $68 \%$ reduction in peak base responses under the Gebze earthquake.

2. For the El Centro earthquake, the $\mathrm{H}_{\infty}$ and the mixed $\mathrm{H}_{2}$ and $\mathrm{H}_{\infty}$ semi-active control method has higher reduction in the peak shear responses, all normed response $\left(J_{6}-J_{9}\right)$, and the peak value of the stroke so that this control method performs averagely on the subjects with regard to accelerations.

3. On the whole, the mixed $\mathrm{H}_{2}$ and $\mathrm{H}_{\infty}$ semi-active control method is the best control method among all the semi-active control strategies because the control method has a good ability to mitigate every evaluated response, and this control method has a robust control gain to generate the appropriate control force. Table III shows the ranking among five different semi-active control algorithms ( $\mathrm{r}$ from 1 to 5) for each case of data set and a specific damper. From all the numerical studies using different types of ground motion data, as shown in Table III, the mixed $\mathrm{H}_{2}$ and $\mathrm{H}_{\infty}$ semi-active control method is a better control algorithm than the others.

4. For the case of virtual MR dampers the passive-on $(2.5 \mathrm{~V})$ control method has $72,68.9$, and $70.8 \%$ reduction in peak base shear responses under El Centro, Mexico, and Gebze earthquakes, respectively. The better semi-active control methods under three different earthquakes are demonstrated as follows. The mixed $\mathrm{H}_{2}$ and $\mathrm{H}_{\infty}$ semi-active control method has $71.6 \%$ reduction in peak base shear responses under the El Centro earthquake.

Based on the numerical study of the control performance among different control strategies on the cable-stayed bridge, the mixed $\mathrm{H}_{2}$ and $\mathrm{H}_{\infty}$ semi-active control method and the FSMC 
Table IIa. Performance indices of the control algorithm using original MR dampers.

\begin{tabular}{lccccc}
\hline Original MR & $\mathrm{H}_{2}$ & $\mathrm{H}_{\infty}$ & Mixed $\mathrm{H}$ & SMC & FSMC \\
\hline$J_{1}$ & 2 & 1 & 4 & 5 & 3 \\
$J_{2}$ & 3 & 1 & 2 & 4 & 5 \\
$J_{3}$ & 2 & 1 & 3 & 5 & 4 \\
$J_{4}$ & 4 & 3 & 1 & 2 & 5 \\
$J_{5}$ & 4 & 2 & 1 & 3 & 5 \\
$J_{6}$ & 3 & 4 & 1 & 5 & 2 \\
$J_{7}$ & 3 & 4 & 1 & 5 & 2 \\
$J_{8}$ & 3 & 4 & 1 & 5 & 2 \\
$J_{9}$ & 3 & 4 & 1 & 5 & 2 \\
$J_{10}$ & 2 & 3 & 5 & 1 & 4 \\
$J_{11}$ & 4 & 2 & 1 & 3 & 5 \\
\hline
\end{tabular}

Table IIb. Performance indices of the control algorithm using virtual MR dampers.

\begin{tabular}{lccccc}
\hline Virtual MR & $\mathrm{H}_{2}$ & $\mathrm{H}_{\infty}$ & Mixed $\mathrm{H}$ & SMC & FSMC \\
\hline$J_{1}$ & 2 & 1 & 3 & 5 & 4 \\
$J_{2}$ & 3 & 1 & 2 & 4 & 5 \\
$J_{3}$ & 2 & 1 & 4 & 5 & 3 \\
$J_{4}$ & 4 & 3 & 1 & 2 & 5 \\
$J_{5}$ & 3 & 2 & 1 & 5 & 4 \\
$J_{6}$ & 3 & 4 & 1 & 5 & 2 \\
$J_{7}$ & 3 & 4 & 1 & 5 & 2 \\
$J_{8}$ & 3 & 4 & 1 & 5 & 2 \\
$J_{9}$ & 3 & 4 & 1 & 5 & 5 \\
$J_{10}$ & 2 & 4 & 3 & 1 & 4 \\
$J_{11}$ & 3 & 2 & 1 & 5 & \\
\hline
\end{tabular}

Table IIc. Performance indices of the control algorithm using original MR dampers under Chi-Chi earthquake data (TCU01).

\begin{tabular}{lccccc}
\hline Original MR & $\mathrm{H}_{2}$ & $\mathrm{H}_{\infty}$ & Mixed $\mathrm{H}$ & SMC & FSMC \\
\hline$J_{1}$ & 4 & 1 & 3 & 5 & 2 \\
$J_{2}$ & 3 & 1 & 2 & 5 & 4 \\
$J_{3}$ & 3 & 2 & 4 & 5 & 1 \\
$J_{4}$ & 4 & 1 & 3 & 5 & 2 \\
$J_{5}$ & 4 & 1 & 3 & 5 & 2 \\
$J_{6}$ & 4 & 1 & 3 & 5 & 2 \\
$J_{7}$ & 4 & 1 & 3 & 5 & 2 \\
$J_{8}$ & 4 & 1 & 3 & 5 & 1 \\
$J_{9}$ & 4 & 2 & 2 & 5 & 5 \\
$J_{10}$ & 3 & 4 & 3 & 5 & 2 \\
$J_{11}$ & 4 & 1 & 32 & 51 & 25 \\
\hline Sum & 41 & 16 & &
\end{tabular}


semi-active methods are recommended for this benchmark problem. The ranking of these control methods is shown in Table III.

\section{CONCLUSIONS}

The objective of this study is to examine various semi-active control algorithms for application to structural control by using MR dampers. The study consists of MR dampers modeling, control circuits, inverse neural network model, and control algorithms. Due to the highly nonlinear characteristics of MR dampers, the neural network system was applied to emulate the inverse dynamic characteristics of MR dampers. Besides, the inverse NN model uses the neural network to predict the required voltage of MR dampers. In this study the input of the inverse NN model includes two consecutive steps of stokes and velocities, the previous step of voltage, and the desired control force, and the output is the required voltage. For the control circuit of a cable-stayed bridge it contains excitations, an evaluation model of the cable-stayed bridge, sensors, control algorithms, and control devices, and every control algorithm uses a reduced model of the cable-stayed bridge to generate the control force.
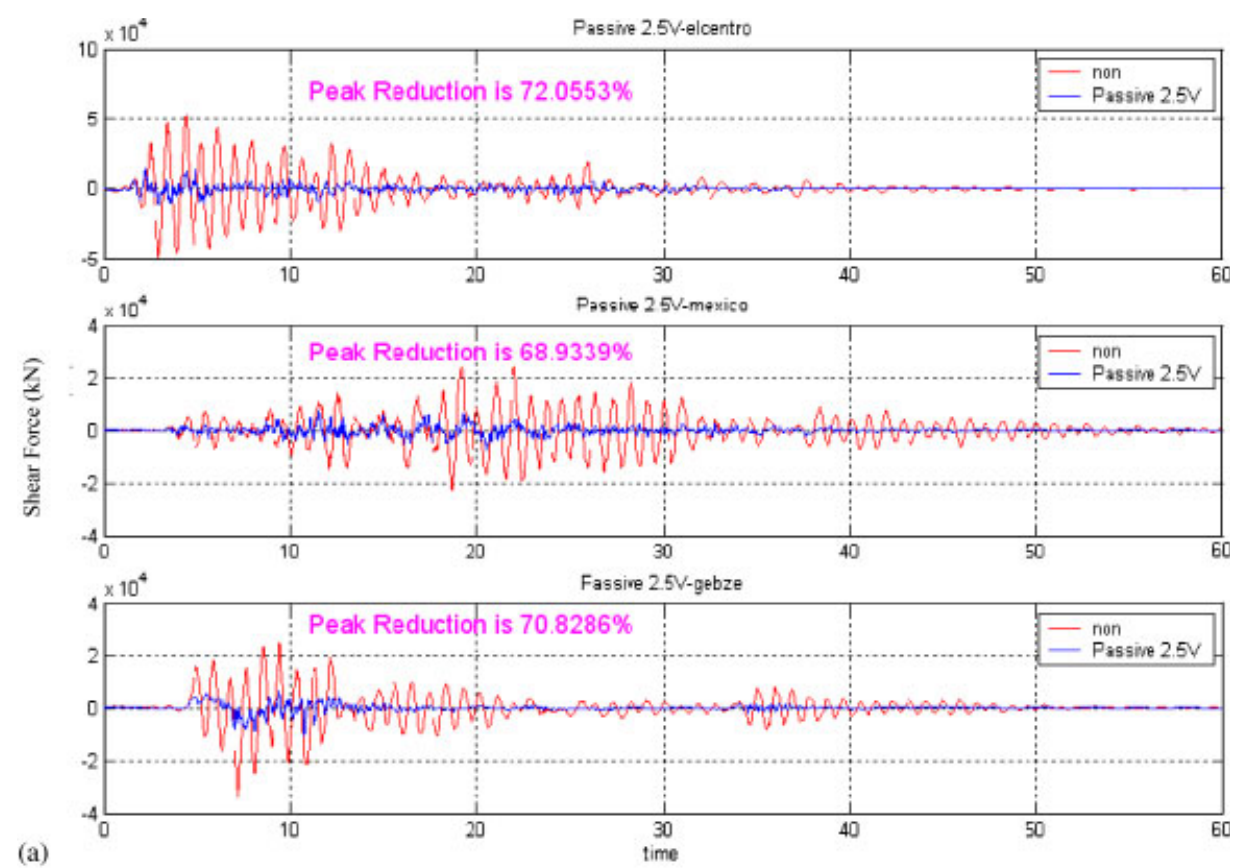

Figure 12. (a) Simulated responses to El Centro, Mexico, and Gebze earthquakes using passive-on (2.5 V) control method of virtual MR dampers (uncontrolled and controlled base shear force record on pier 2); (b) simulated responses to El Centro, Mexico, and Gebze earthquakes using mixed $\mathrm{H}_{2}$ and $\mathrm{H}_{\infty}$ control method of virtual MR dampers (uncontrolled and controlled base shear force record on pier 2); (c) simulated responses to El Centro, Mexico, and Gebze earthquakes using FSMC method of virtual MR dampers (uncontrolled and controlled base shear force record on pier 2). 

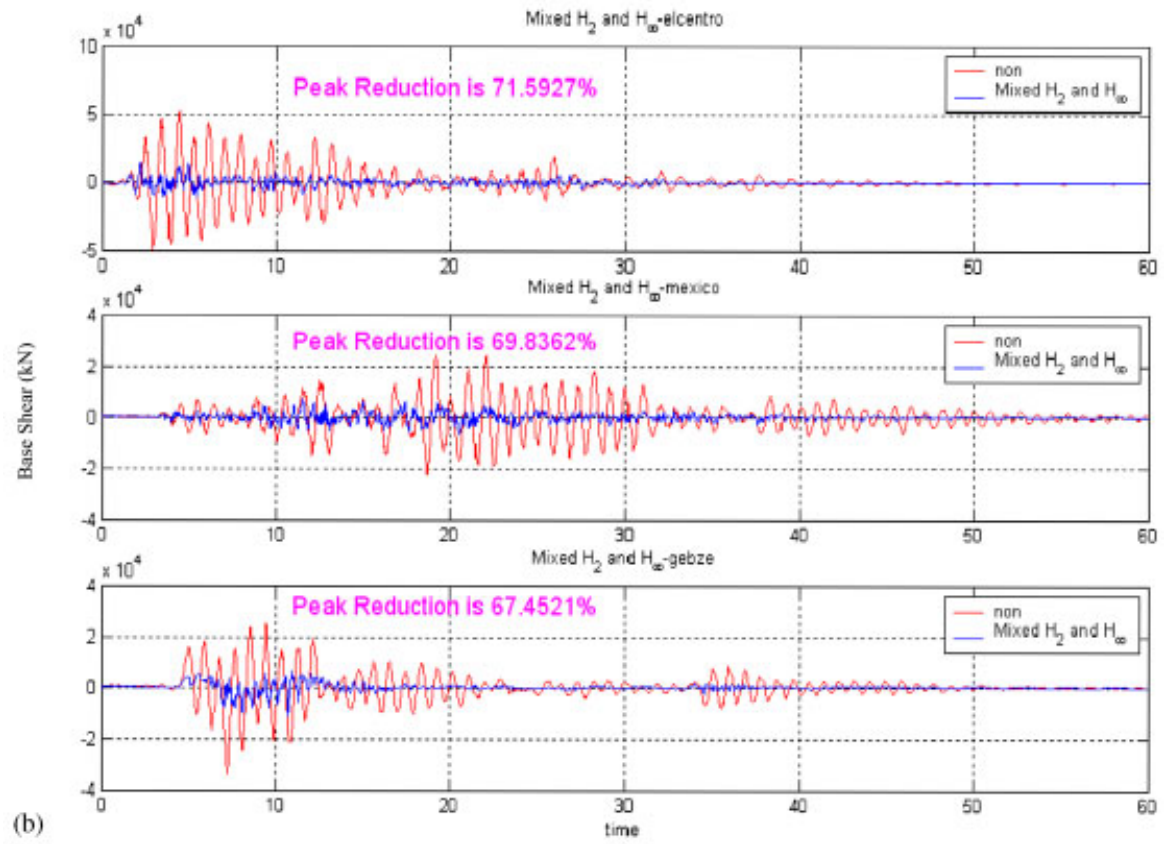

(b)
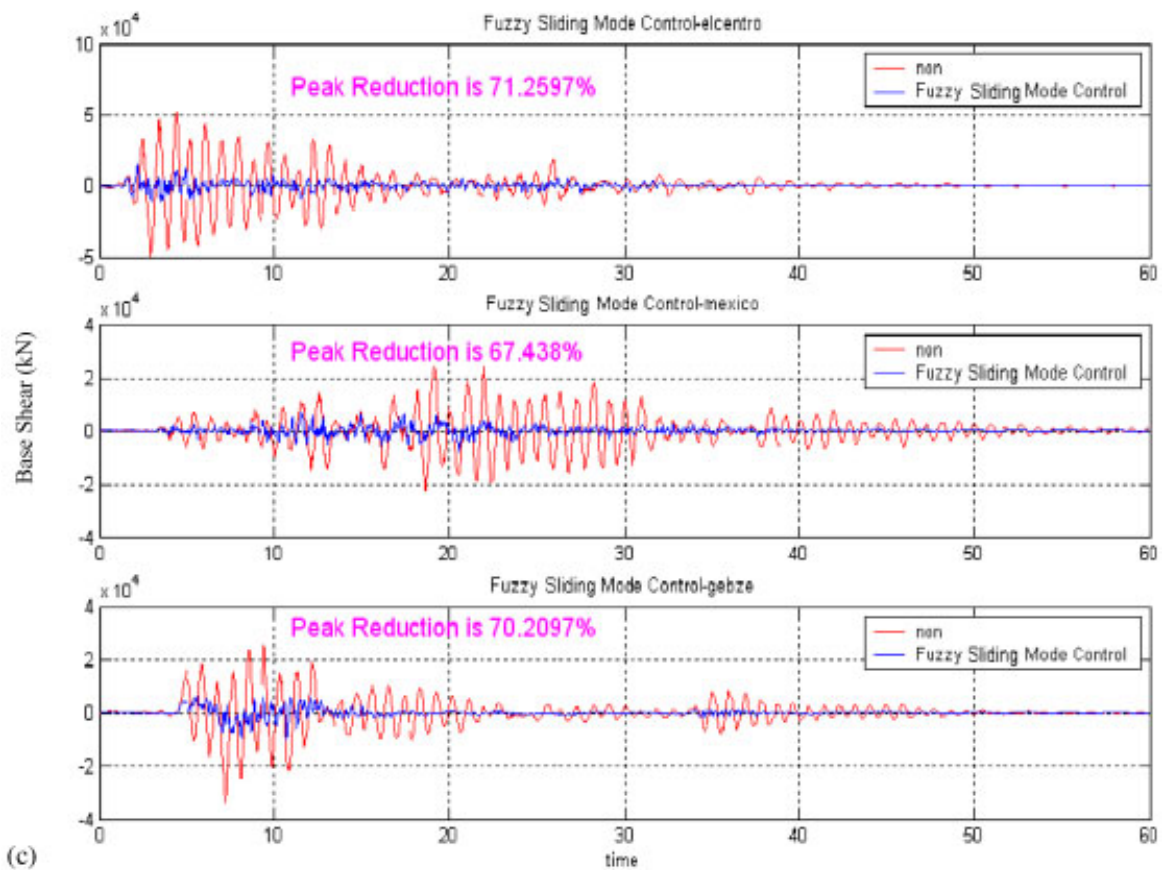

Figure 12. Continued. 

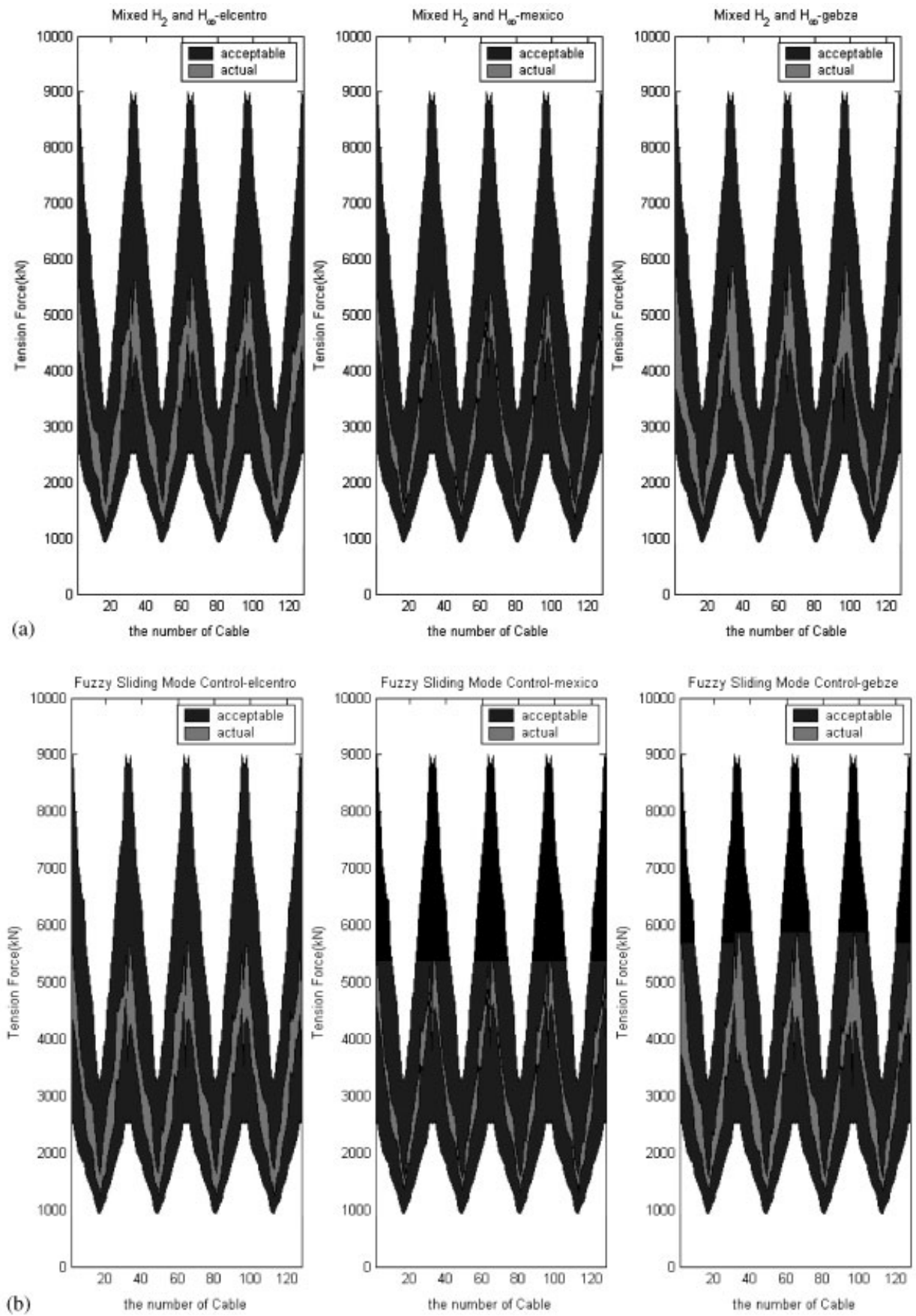

Figure 13. (a) Simulated responses of controlled cable tension using mixed $\mathrm{H}_{2}$ and $\mathrm{H}_{\infty}$ control method of virtual MR dampers under El Centro, Mexico, and Gebze earthquakes; (b) simulated responses of controlled cable tension using FSMC method of virtual MR dampers under El Centro, Mexico, and Gebze earthquakes. 

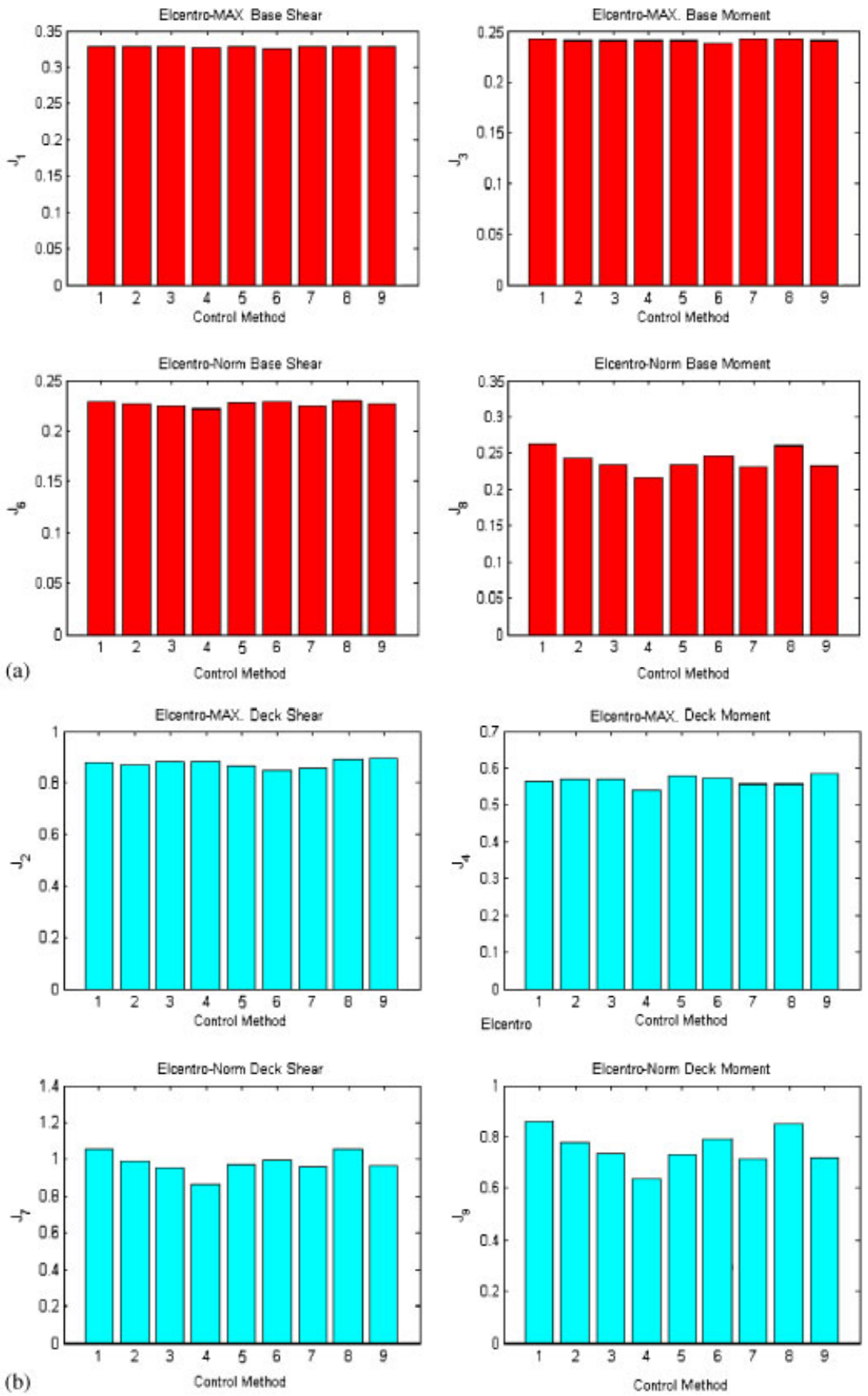

Figure 14. (a) Comparison of performance indices $\left(J_{1}, J_{3}, J_{6}\right.$, and $\left.J_{8}\right)$ of the cases using virtual MR dampers under the El Centro earthquake; (b) comparison of performance indices $\left(J_{2}, J_{4}, J_{7}\right.$, and $\left.J_{9}\right)$ of the cases using virtual MR dampers under the El Centro earthquake. 
Table III. Ranking of five different semi-active control algorithms.

\begin{tabular}{lccccc}
\hline $\begin{array}{l}\text { Control method } \\
\text { (semi-active control) }\end{array}$ & $\mathrm{H}_{2}$ & $\mathrm{H}_{\infty}$ & Mixed H & SMC & FSMC \\
\hline $\begin{array}{l}\text { Original MR damper } \\
\text { (conventional data) }\end{array}$ & 4 & 3 & 1 & 5 & 2 \\
$\begin{array}{l}\text { Virtual MR damper } \\
\text { (conventional data) }\end{array}$ & 4 & 3 & 1 & 5 & 2 \\
$\begin{array}{l}\text { Original MR damper } \\
\text { Chi-Chi earthquake) }\end{array}$ & 4 & 1 & 2 & 5 & 3 \\
$\begin{array}{l}\text { Virtual MR damper } \\
\text { (Chi-Chi earthquake) }\end{array}$ & 4 & 1 & 2 & 5 & 3 \\
\hline Sum & 16 & 8 & 6 & 20 & 10 \\
\hline Ranking & 4 & 2 & 1 & 5 & 3 \\
\hline
\end{tabular}

Two types of MR dampers are employed to control the model structure essentially. One is the small-scale MR dampers provided by NCREE with $7 \mathrm{kN}$ maximum resisting force for each damper. In this study the capacity of this damper was amplified to 100 so as to adapt to the large-scale bridge. The other type of MR dampers is created with the rule of the bilinear model using reasonable parameters of the model. The second type of MR dampers are called 'virtual' MR dampers in this study and the range of the voltage command and the capacity of the control force are $0-0.25 \mathrm{~V}$ and $1000 \mathrm{kN}$, respectively. Among these researches, some conclusions can be made.

1. For modeling the MR damper, the modified bi-viscous model and the bilinear model can effectively simulate the characteristics of MR dampers. The modified bi-viscous model can express the behavior of the force-stroke and force-velocity diagrams of MR dampers completely and the bilinear model can approximately describe the hysteretic behavior MR dampers based on the simple mathematical form of the force-velocity relation without complicated computation.

2. Several semi-active control algorithms have been evaluated for application in a structural control system using multiple MR dampers. For the control of a cable-stayed bridge, the numerical simulation results demonstrate that the performance of the proposed control design is nearly the same as that of the passive control system. Compared with the uncontrolled bridge case the proposed control strategies also significantly reduce the peak and the normalized responses of shears and moments at the base and the deck, especially the mixed $\mathrm{H}_{2}$ and $\mathrm{H}_{\infty}$ semi-active control method and the FSMC semi-active method. Besides, the passive-on control system for use of the cable-stayed bridge control is also recommended. The mixed $\mathrm{H}_{2}$ and $\mathrm{H}_{\infty}$ semi-active control method is the better control method in this case because the control method has a good ability to mitigate every evaluated response, and this control method has a robust control gain to generate the appropriate control force.

3. For the cable-stayed bridge control, the numerical simulation results demonstrated that the performance of the proposed control design is nearly the same as that of the passive control system. But the passive control system for this benchmark problem is a little better than the 
semi-active control methods, especially the passive-on control method $(2.5 \mathrm{~V}$ passive control method with virtual MR dampers and $1.2 \mathrm{~V}$ passive control method with original MR dampers). In general, the dynamic characteristics of MR-damper is similar to Figure 1; it has proved to be a useful device to control a structure. In this study the semi-active MRdamper with mix $\mathrm{H}_{2}$ and $\mathrm{H}_{\infty}$ control strategy did prove to be have efficient performance, but for system reliability the passive MR-damper was recommended as for control of the structure.

\section{ACKNOWLEDGEMENTS}

This research was supported by the National Science Council, Taiwan, under Grant NSC92-2211-E002-087.

\section{REFERENCES}

1. Dyke SJ, Spencer BF, Sain MK, Carlson JD. Modeling and control of magnetorheological dampers for seismic response reduction. Smart Materials and Structures 1996; 5:565-575.

2. Wereley NM, Pang L, Kamath GM. Idealized hysteresis modeling of electrorheological and magnetorheological dampers. Journal of Intelligent Material Systems and Structures 1998; 9:642-649.

3. Wen YK. Method of random vibration of hysteretic systems. Journal of Engineering Mechanics (ASCE) 1976; 102 (EM2):249-263.

4. Stanway R, Sproston JL, Stevens NG. Non-linear modeling of an electro-rheological vibration damper. Journal of Electrostatics 1987; 20:167-184.

5. Chang CC, Zhou L. A recurrent neural network emulator for the inverse dynamics of an MR damper. Advances in Structural Dynamics 2000; 1:365-372.

6. Yang JN, Akbarpour A, Ghaemmaghami P. New optimal control algorithms for structural control. Journal of Engineering Mechanics (ASCE) 1986; 113:1369-1386.

7. Limebeer DJN, Anderson BDO. A Nash game approach to mixed $\mathrm{H}_{2} / \mathrm{H}_{\infty}$ control. IEEE Transactions on Automatic Control 1994; 39:69-82.

8. Utkin VI. Sliding Modes in Control and Optimization. Springer: New York, 1992.

9. Moon SJ, Bergman LA, Voulgaris PG. Sliding mode control of cable-stayed bridge subjected to seismic excitation. Journal of Engineering Mechanics (ASCE) 2003; 129(1):71-78.

10. Hwang GC, Lin SC. A stability approach to fuzzy control design for nonlinear systems. Fuzzy Sets and Systems 1992; 48:279-287.

11. Jansen LM, Dyke SJ. Semi-active control strategies for MR dampers: a comparative study. Journal of Engineering Mechanics (ASCE) 2000; 126(8):795-803.

12. Caicedo JM, Dyke SJ, Moon SJ, Bergman LA, Turan G, Hague S. Phase II benchmark control problem for seismic response of cable-stayed bridges. Journal of Structural Control 2003; 10:137-168. 